\title{
Protein Engineering: Advances in Phage Display for Basic Science and Medical Research
}

\author{
Elena K. Davydova \\ The University of Chicago, Department of Biochemistry and Molecular Biology, Chicago, IL 60637, USA \\ e-mail:edavydov@uchicago.edu
}

Received August 26, 2021

Revised October 28, 2021

Accepted November 2, 2021

\begin{abstract}
Functional Protein Engineering became the hallmark in biomolecule manipulation in the new millennium, building on and surpassing the underlying structural DNA manipulation and recombination techniques developed and employed in the last decades of 20th century. Because of their prominence in almost all biological processes, proteins represent extremely important targets for engineering enhanced or altered properties that can lead to improvements exploitable in healthcare, medicine, research, biotechnology, and industry. Synthetic protein structures and functions can now be designed on a computer and/or evolved using molecular display or directed evolution methods in the laboratory. This review will focus on the recent trends in protein engineering and the impact of this technology on recent progress in science, cancer- and immunotherapies, with the emphasis on the current achievements in basic protein research using synthetic antibody (sABs) produced by phage display pipeline in the Kossiakoff laboratory at the University of Chicago (KossLab). Finally, engineering of the highly specific binding modules, such as variants of Streptococcal protein $G$ with ultra-high orthogonal affinity for natural and engineered antibody scaffolds, and their possible applications as a plug-and-play platform for research and immunotherapy will be described.
\end{abstract}

DOI: $10.1134 / \mathrm{S} 0006297922140127$

Keywords: phage display, immunotherapy, synthetic antibody, crystallization chaperones, fiducial markers, BiTEs, bi-Fabs

In loving memory of Lev P. Ovchinnikov, great scientist, wise mentor, and dear friend

\section{INTRODUCTION}

"The power of evolution is revealed through the diversity of life" - this is the introductory sentence of the announcement for the 2018 Nobel Prize in chemistry awarded to Frances H. Arnold for the directed evolution of enzymes, and to George P. Smith and Gregory P. Winter for the phage display of peptides and antibodies. Now, scientists have taken control of evolution and can use it for purposes that bring the greatest benefit to

Abbreviations: BiTEs, bi-specific T-cell engagers; CDR, complementarity-determining region; $\mathrm{CH} 1-\mathrm{CH} 3$, constant regions of the heavy chain; CL, constant domain of the light chain; Fab, fragment antigen binding; Fc, fragment crystallizable; HC, heavy chain; KossLab, Dr. A. A. Kossiakoff laboratory at the University of Chicago; LC, light chain; sAB, synthetic antibody; scFv, single chain fragment variable; GA1, engineered variant of protein $\mathrm{G}$ domain $\mathrm{C} 2$; $\mathrm{VH}$, variable domain of the heavy chain; VL, variable domain of the light chain. humankind. Enzymes produced through directed evolution are used to manufacture everything from biofuels to pharmaceuticals, and antibodies evolved using phage display combat autoimmune diseases and cure cancer [1]. Although, due to the new algorithms and advances in computer performance, novel and improved synthetic protein structures and functions can now be designed entirely in silico by rational molecular and de novo design [2], synergistic combination of the computational design and in vitro evolutionary approaches produces variants superior to those that could be generated by the design only [3]. Thus, Protein Engineering, a multidisciplinary field that organically integrates chemistry, physical and molecular biology, protein and computer sciences, has arrived to complement and succeed to Gene Engineering, one of the major achievements in Molecular Biology.

Arnold's seminal invention of directed evolution in 1996 [4-7] resulted in the tremendous boost to enzymeengineering possibilities well surpassing the limits of 
nature. Highly artificial selection environments, diverse catalytical reactions and non-natural substrates, incorporation of synthetic amino acids and chemical modifications into proteins, all these achievements have drastically broadened the boundaries of potential applications for the engineered enzymes: efficient and cost-effective, green, and sustainable biocatalysts were produced by the directed evolution for current industrial, pharmaceutical, and research applications [8].

Traditionally, the term "directed evolution" has been strictly referring to the Arnold's method of enzyme improvement through iterative cycles of protein diversification at the gene level (using random mutagenesis) and high-throughput screening of the encoded variants at the protein level. Alternatively, in phage display, the DNA variability is introduced by the initial library of billions of protein or peptide variants, and then it undergoes a huge reduction in the sequential rounds of panning and amplification, resulting in a limited number (usually, dozens or less) of unique phage clones. In both cases, amplification of the selected molecular variants requires an unambiguous physical genotype-phenotype linkage, which is readily provided by a single cell or a phage particle. As mentioned above, principal distinction between the phage display and directed evolution is that DNA does not undergo further diversification between the rounds of phage display panning. Therefore, molecular evolution achieved in phage display by the sequential enrichment of the most-fitted variants is rather reminiscent of the genetic bottleneck effect in nature, unlike the gradual canonical directed evolution which, step by step, selects more and more evolutionary advanced molecules. By its very nature, based on molecular selection by the phage binding, the phage display technology cannot address modulations and tuning of enzyme catalysis and is usually directed toward enhancement of the structural stability of the protein and binding affinities to antigens, partner proteins, or ligands, demonstrating its tremendous power particularly for specific peptide and antibody generation and maturation.

Since Smith and Winter published their pivotal studies in 1980s-1990s [9-14], the scope and capabilities of phage display have been enormously expanded [15-20]. Construction of large numbers of phage display peptide and antibody libraries containing $10^{11-12}$ unique members have been achieved [18, 21, 22] and are commercially available (New England BioLabs, MoBiTec GmbH, and Creative Biolabs, Shirley, NY, USA)

Synthetic antibodies, tailored to a specific antigen or antigen epitope hugely helped to overcome protein structure determination challenges as well as powered up many medical endeavors. Multiple modifications of the original technology of peptide phage display, including cyclic and artificially linked peptides [23], resulted in varieties of the cancer-specific ligands validated in cancer diagnostics and therapy [24].
Undoubtedly, the progress in protein engineering greatly affects the landscape of cancer- and immunotherapeutics beyond the production of new potent peptidebased ligands or synthetic and in vitro matured antibodies. Applications of the antibody-drug conjugates, bispecific antibody-based molecules, and other antibody derivatives are empowered by the highly discriminative antibodydriven targeted cell delivery and well-controlled effect on the cells of choice. The targeted cell type is defined by the antibody specificity to one of the cell-surface receptors, and its fate - by the built-in effector moiety. The antibody-drug conjugates are able to kill cancer cells by binding to the tumor-specific receptors and directionally dispatching their "payloads" - potent cytotoxic small molecules [25]. Cytolytic effect of the bispecific T-cell engagers (BiTEs) depends on their ability to induce synapse formation between the cancer and $\mathrm{T}$ cells by bridging together their receptors targeted by two specificities $[26,27]$. In addition of being a part of anti-cancer therapy, the antibody-based reagents could specifically inhibit inflammatory pathways and have been developed to treat diseases and conditions caused by excessive inflammation and autoimmunity [28, 29]. To date, hundreds of different antibody-based formats have been engineered for therapeutic purposes, with many representing BiTEs [30], and new constructs are constantly emerging [31].

Here, we review the antibody phage-display technology in detail - from the library construction methods to synthetic antibody ( $\mathrm{sAB}$ ) production and characterization. Using the phage-display pipeline established in the Dr. Kossiakoff Laboratory (KossLab) at the University of Chicago, as an example, the state-of-the-art progress in sABs custom-tailoring for challenging applications, such as protein structure determination of membrane proteins is addressed. Then, the sABs high potency as energy and functional probes, conformational and crystallization chaperons, fiducial markers for single-particle cryo-electron microscopy (cryo-EM), and superb antigen-binding reagents is discussed. Next, reciprocal maturation of the uniquely specific affinity between the protein $\mathrm{G}$ (variant GA1) and the engineered $\mathrm{sAB}$ scaffold (Fab ${ }^{\mathrm{LRT}}$ ) aiming further higher-order construction efforts, such as multivalent and multi-specific antibody arrangements, is described. The resulting novel, easily manipulatable, multifunctional, and sturdy GA1-based plug-and-play platform utilizing Fab ${ }^{\mathrm{LRT}}$ molecules as the interchangeable elements, and its possible applications in basic science, biotechnology, and medicine are considered in the conclusion.

\section{ANTIBODY PHAGE DISPLAY ANTIBODY FORMATS}

Immunoglobulin $\mathrm{G}(\mathrm{IgG})$ is the most common type of human antibodies. IgGs, which are complex, bi-valent, 
a

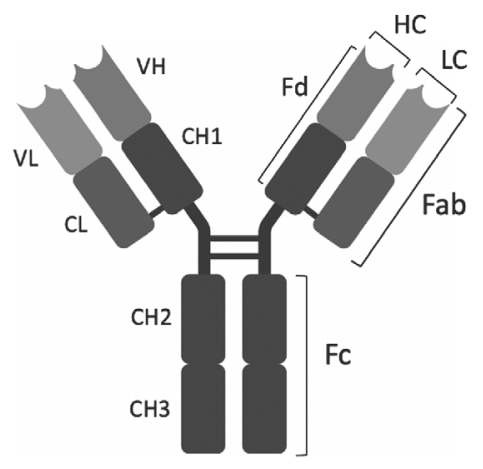

Human IgG b

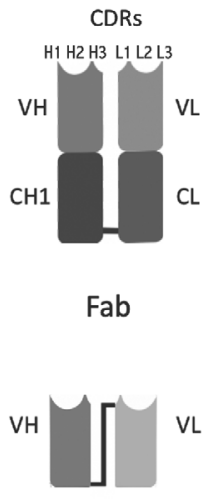

scFv

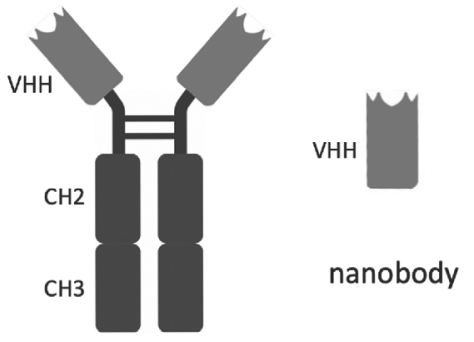

Camelid IgG

Fig. 1. Antibody formats used in phage-display technologies. a) Schematic structures of human IgG antibody and fragments: HC, heavy chain; LC, light chain; $\mathrm{VH}$, variable domain of the heavy chain; VL, variable domain of the light chain; $\mathrm{CH} 1-\mathrm{CH}$, constant regions of the heavy chain; CL, constant domain of the light chain; Fc, fragment crystallizable; Fab, fragment antigen binding; Fd, heavy chain of the Fab; CDR, complementarity-determining regions of the heavy chain (H1-H3) and of the light chain (L1-L3); scFv, single chain fragment variable; b) camelid heavy-chain IgG antibody and VHH nanobody depictions. The schemes were generated using Biorender (www.biorender.com).

multi-subunit proteins with many disulfide bonds and are unsuitable for bacterial expression. Therefore, smaller, mono-valent antigen-binding fragments such as scFv (single chain fragment variable) or Fab (fragment antigen-binding) are the most often used formats for phage display [32] (Fig. 1a). Fab molecule is a heterodimer containing a full-length light chain (Fab) and an Fd fragment of a heavy chain ( $\mathrm{VH}$ and $\mathrm{CH} 1$ domains) usually linked together by a disulfide bond at their C-termini (this linkage is not essential for heterodimerization [33]. These chains, of approximately equal masses, comprise $\sim 50 \mathrm{kDa} F a b$. The scFv molecule is half a size $(\sim 25 \mathrm{kDa})$ and consists of two variable domains (VH and VL) fused together by a small flexible peptide linker of $\sim 15$ aa (Fig. 1a) Notably, while Fabs generally maintain full antigen-binding affinity upon reformatting into the full-size IgG and back (taking into account the 2-fold difference in the format valency), the scFv affinity can be drastically changed upon reformatting and sometimes is influenced by the VH/VL domain mutual orientation and/or linker length, and, also, this format is prone to oligomerization [34, 35].

Both scFvs and Fabs have been displayed on the bacteriophage surface in the Winter's pioneering works [24, 36] and are still the most popular for construction of sAB phage display libraries. However, combinatorial arrays [37] and some other new formats, such as nanobodies representing a single $\mathrm{VHH}$ domain of an unusual homo-dimeric camelid IgG [38] (Fig. 1b), are successfully challenging the originals. A dozen of therapeutic antibodies have been commercialized that have been discovered by means of antibody-displaying phage libraries including the world best-selling rheumatoid arthritis treating antibody adalimumab [39], with many more in the pipeline [40].

In addition to phage display, a great variety of display platforms have been developed to better suit rationale and particularity of the selections. Large libraries of recombinant cell-surface proteins were constructed and successfully applied for display on the baculovirus and bacterial, yeast, insect, and mammalian cells [41-44]. Molecular displays on the surface of eukaryotic cells are highly permissive for multi-domain proteins and multi-molecular complexes, as well as for synthesis of functional mammalian proteins undergoing essential posttranslational modifications that are supported by the eukaryotic cytoplasm [45]. The alternative cell-free methods, like ribosome display [46] and mRNA display [47] offer their own advantages, such as speedy turnover, enormous library size, and potential incorporation of non-natural amino acids and chemical modifications into the proteins. However, despite of all the advantageous features of other display techniques mentioned above, phage display remains the most popular display platform today.

\section{M13 BACTERIOPHAGE}

This chapter is dedicated to M13 bacteriophage structure and physiology that have been studied for decades and can be skipped by the educated readers, however, it contains information important for better understanding of the M13 phage display design specifics, advantages, and limitations.

Bacteriophages M13, fd, and f1 belonging to Ff (Fpilus specific filamentous) phages and almost identical in 
every aspect ( $98 \%$ identity at the DNA level) were the first used in phage display [48]. Later, the tailed bacteriophages T4 and T7 have also been successfully tested as display platforms [49]. The most developed of those, T7 phage display, demonstrate several particular advantages over the classic M13 platform, that could be important in some special applications: (i) T7 phage contains double stranded DNA, which is more stable and less prone to mutation during replication as compared to the singlestranded M13 phage genomic DNA; (ii) foreign cDNA or bacterial genomic libraries could be directly inserted into the T7 phage ds DNA genome; (iii) T7 phage does not depend on a bacterial protein secretion pathway and has a lytic life cycle. However, the M13 phage has its own pluses, making it the most developed and popular antibodydisplay platform to date.

M13 phage has high capacity for replication and can accommodate large foreign DNA as a highly transformable M13-based dsDNA phagemid vector, mimicking phage replicative form (RF) and producing circular ssDNA phagemid molecules that can be packaged into infectious phage particles. M13 bacteriophage is nonlytic: the progeny phage filaments are secreted from the intact bacterial cell (although growth rate of the infected bacteria slows down). Consequently, M13-based phage display libraries can be stored as frozen $E$. coli stocks. The extraordinary stability of M13 bacteriophage particles in a wide range of temperature, $\mathrm{pH}$, and solvent composition allows for prolonged incubations under various conditions of the phage-displayed antibody libraries during the experimental procedures, and the library storage in frozen or desiccated state for years [50].

The single-stranded circular phage M13 genomic DNA (6400 nt) encoding 11 phage-specific proteins in total is protected by the stable protein capsid composed of approximately 2,700 copies of the major coat protein gp8 forming the cylinder, and several copies of four other minor coat proteins at either end of the phage filament: gp3 (five copies) and p6 at one end; gp7 and gp9 at the other. The infectious M13 phage filament has a length of $<1 \mu \mathrm{m}$ and a diameter of $\sim \mathrm{nm}$ [51].

The first step of M13 infection involves recognition of the F pilus on the surface of the E. coli by gp3, followed by gp3 binding to the tolA-based bacterial complex that bridges between the outer and inner membrane of the host [32]. After penetration through the periplasm the phage genomic ssDNA is got stripped of gp8 and released into the host cytoplasm, where it is rapidly converted to a RF dsDNA by E. coli enzymes. This initiates transcription from 5 constitutive promoters, producing mRNAs encoding all 11 phage proteins. Hundreds of the singlestranded copies of the M13 genome are made by the mechanism called rolling-circle replication using RF DNA as a template: some of them are converted into more RF molecules, while the majority are destined to be packaged into the phage progeny. As freshly synthesized phage proteins accumulate, $\sim 750$ gp5 dimers cooperatively cover the whole length of M13 circular ssDNA except for a short 77 base-long section, known as the packaging sequence. This gp5 shell packs genomic DNA into a flexible rod protected from nucleases, thus forming the intracellular precursor of the extracellular virion. Binding of the DNA packaging-signal at the forward end of the precursor by the assembly protein complex in the inner membrane initiates the phage extrusion. Next, the membrane-associated gp8 oligomers are built into a spiraling array around phage DNA, replacing gp5. This nascent filament passes through the periplasm-spanning channel and a porin-like structure composed of 14 subunits of gp4. Finally, the inner membrane inserted gp3 and gp6 proteins are attached to the proximal end of the extruding virion particle completing the phage assembly.

The details of M13 phage replication and assembly are reflected in a vector construction for displaying of foreign polypeptides as coat-protein fusions on the phage. As a rule, the gene of interest is fused to the gene of one of the coat proteins cloned into the plasmid, which carries both plasmid dsDNA and f1 ssDNA origins of replication, f1 DNA packaging signal, and an antibiotic resistance gene [52]. This vector, called a phagemid, can be transformed and amplified in E. coli as a regular plasmid. Since this phagemid mimics RF of the phage DNA, the phagemid-transformed $\mathrm{F}$ pilus + cells can efficiently produce ss phagemid DNA and encapsidate it into the infectious phage progeny with the assistance of the M13 helper phage infection that provides all the phage proteins required for phage biogenesis. A mutation, that makes $\mathrm{f} 1$ DNA packaging signal of helper phage defective is disadvantageous for packaging of the helper-phage ssDNA, and thus favors formation of the phagemid-containing virions. Since these virions display the phagemid-encoded fusion protein, it provides physical link between the phage genotype and phenotype, realizing the key principle for phage-display as a molecular evolution-directed system [53]. In order to eliminate the need for the helper phage and avoid the helper-phage contamination in the phage progeny, bacterial "packaging" cell lines containing M13-phage based helper plasmids lacking the ssDNA replication origin, have been constructed [54], however, the classic way featuring the helper-phage superinfection is still very popular.

By now, every M13 coat protein has been tried for molecular display as both $\mathrm{N}$ - and $\mathrm{C}$-terminal fusions [55]. Nature of the coat protein to be used as the fusion partner as well as size and structural characteristics of the proteins chosen to be displayed should be considered for the display success. As a rule, large, structurally complex, and multi-subunit proteins, like antibodies, cannot be expressed in bacterial cells, and this automatically makes them inappropriate for bacteriophage display. Additionally, fusion proteins could be rejected after the synthesis at different stages of phage maturation. Such obstacles as 
steric hindrance or wrong surface texture could prevent some bulky, or highly charged, or overly hydrophobic fusion proteins from proper incorporation into the phage particles both prior to phage assembly - upon membrane association, or during recognition by the assembly complex, or after the capsid completion - at the phage extrusion step due to insufficiently wide gp4 channel opening for the particle decorated with a fully folded and assembled fusion proteins. While the major coat protein $\mathrm{gp} 8$ supports high multivalency of the display and is frequently used for the display of peptide libraries, even antibody fragments are too large for gp 8 display. Historically, gp3 was the first display support that was successfully demonstrated to work in the antibody libraries displaying scFvs or Fabs [24, 36] and is the most commonly used today. To be displayed, usually the antibody fragment is fused to the $\mathrm{N}$-termini of gp3 or its C-terminal domain, which itself assembles into a capsid tip, while it is the $\mathrm{N}$-terminal domain of gp3, which recognizes the $E$. coli F-pilus. The wild-type gp3, product of the copy of unmodified g3 in the helper-phage DNA, is incorporated into the pentameric gp3 arrays at a higher proportion over the fusion protein, thus ensuring infectivity of the progeny virions [56, 57]. Moreover, the ratio of the fusion to wild type gp3 available for the phage assembly is such, that not every progeny particle displays the antibody. However, this is not usually problematic for the library performance, since the standard antibody phage library has a density of $10^{13} \mathrm{cfu} / \mathrm{ml}$, which is 100 times greater than the typical antibody libraries.

\section{M13 PHAGE ANTIBODY LIBRARIES}

Natural antibody libraries. Antibody-displaying phage libraries can be either natural or synthetic, or both, depending on the origin of the diversity component, incorporated into the antibody-fragment scaffold. Diversity of the natural libraries is provided by the antibody repertoire acquired in the live immune system by gene rearrangement [12]. Each of the three major human immunoglobulin gene loci (one for $\mathrm{HC}$ and two - lambda and kappa, for LC, light chain), contains multiples of variable $(\mathrm{V})$, diversity $(\mathrm{D}$, only for $\mathrm{HC})$ and joining $(\mathrm{J})$ genes. $\mathrm{V}(\mathrm{D}) \mathrm{J}$ recombination, different in each individual lymphocyte, causes one random copy of each type of the gene segment to be sequentially joined together, generating $1 \times 10^{11}$ unique heavy-chain sequences and an enormous potential number of naïve paired antibody perhaps in the range of $10^{16}-10^{18}$ unique antibody sequences [58]. Real diversity of the naïve human antibody repertoire is estimated to be at least $10^{12}$ unique combinations. Since the number of peripheral blood B cells in a healthy adult human is on the order of $5 \times 10^{9}$, the circulating B cell population samples only a microscopic fraction of this diversity.
Antibody diversity is, mostly, present in their six complementarity determining regions (CDRs), highly variable structural loops undergoing clonal selection in the immune system. Three of them: L1, L2, and L3 are located in VL, and three: H1, H2, H3 - in VH. In general, the CDR loops in $\mathrm{HC}$ are more frequently involved in antigen binding than those in the LC. Contribution of each of the six CDR loops to antigen recognition is individual and each residue position within a single CDR may play a completely different role depending on the antigen-antibody complex [59]. Five of the six CDRs of a restricted variety and length from 3 to 15 residues adopt a limited number of backbone conformations, while $\mathrm{H} 3$ is longer, more compositionally and structurally diverse [60] and is considered to be the most important for antigen recognition [61].

Standard natural combinatorial antibody libraries are constructed by random pairing of $\mathrm{VH}$ and VL repertoires from cDNA of the pool of mammalian B cells into a phagemid vector using PCR cloning. The antibody assortment can be enriched for the desired-target binders by prior immunization. The resulting immune library does not need to be as large as naïve libraries, since the immunized pool of lymphocytes would contain multiple proliferated B-cell clones targeting the antigen. Some naïve antibody libraries represent $10^{11}$ individual clones or more $[18,21,22]$, reaching practical limit of the phage antibody library size preset around $10^{12}$ value, due to the technical limitation of bacterial transformation, culturing, and storage [62]. While theoretical diversity of the naïve combinatorial libraries is much higher than their achievable size, there is significantly less variety of the naturally paired $\mathrm{VH}-\mathrm{VL}$ in the mammalian immune system. A miniature phage library containing $\sim 10^{6}$ naturally paired scFvs derived from cDNA of the individual B cells was constructed using a single-cell microfluidics that allowed to mine for an extremely rear antibody variants as well as to display natural antibody paratopes from hundreds of donors in one phage library [63]. This technique was advanced to high-throughput single-cell activitybased screening and sequencing platform of thousands of antibodies from the mice immune cells and activated human memory cells [64]. At present, there are dozens of commercially available natural antibody libraries in multiple formats, including chicken scFvs and camelid VHHs (Creative Biolabs).

Natural antibody libraries have been proven to be excellent suppliers of high-quality antibodies suitable for therapeutic applications in medicine [65] and veterinary [66], and many such antibodies are in clinical use or at various stages of therapy development [40].

Synthetic antibody libraries. Most of the SAB libraries use the natural Ig framework, however, a number of modules representing protein-binding polypeptides from natural sources were engineered into the stable spatial arrangements of several diversified loops fea- 
turing compact antigen-binding structures [67]. When implemented in the phage display libraries, they yielded high-quality non-Ig binders that could be of great interest for basic and applied scientific research due to their robust folding, high solubility, and small size. A number of non-Ig binders for health-relevant targets are, presently, at different stages of clinical trials [68]. Nonetheless, despite the constant challenge from other emerging formats, the classic libraries based on the Igfragment scaffolds remained the most desirable for $\mathrm{sAb}$ production [69].

The CDR loops of a SAB library need to be designed so that the resulting library is enriched with diverse, yet nature-like sequences, different in length and composition [70]. As discussed above, the pre-existing variety of CDRs incorporated into the natural antibody libraries originates from the operational immune system in vivo [12], therefore, quality of the natural library depends, mostly, on the efficiency of the variety incorporation into the library, i.e., on the library size. On the contrary, theoretical number of the possible combinations in the case of synthetic CDR variants has almost no upper limit: e.g., complete randomization of just a single piece of 10 codons produces more than $10^{13}$ ( $20^{10}$ including stop codons) of clone variations - amount, practically unattainable in a phage library. Therefore, smart diversification strategy considering each CDR length variability and randomization method as well as their magnitude became the key issue in the design of a quality $\mathrm{SAB}$ library [69].

The early examples of $\mathrm{sAB}$ libraries incorporated random CDR sequences of different length by means of degenerate oligonucleotides synthesizes from different nucleotide mixtures at different codon positions [71]. Due to genetic code redundancy, all 20 amino acids are encoded by NNK or NNS degenerate codon ( $\mathrm{N}$ is any of the four deoxyribonucleotides; $\mathrm{K}=\mathrm{G}$ or $\mathrm{T} ; \mathrm{S}=\mathrm{G}$ or $\mathrm{C}$ ), removing two out of three stop codons (TGA and TAA, but not TAG) and reducing the number of possible codons from 64 to 32, thus, decreasing the number of unique DNA sequences by two-fold. Other combinations of nucleotide mixtures can further reduce the number of codons and encoded amino acids in the sets. Examples of the commonly used degenerate codons in CDR design include KMT ( $\mathrm{M}=\mathrm{A}$ or $\mathrm{C})$ that encodes Ala, Asp, Ser or Tyr; WMC (W = A or T) for Asn, Ser, Thr, or Tyr; and RRT ( $R=$ A or G) for Asn, Asp, Gly, or Ser. Degenerate oligonucleotides are easy to design and are costefficient - highly functional antibody libraries of $10^{8}-10^{9}$ unique clones have been constructed using this method [72]. Although the smaller nucleotide sets are highly desirable due to the library size limitations, there are many mutually exclusive amino acids in these sets. This problem is resolved by the more expensive but fully codon-specific synthetic methods, such as trinucleotide phosphoramidite synthesis [73] or dsDNA triplet-based
Slonomics [74], dictating incorporation of only the chosen codons at the desired ratio into each position. Consequently, CDRs can be designed to have a smaller number of variants, while featuring more nature-like distribution of amino acids, thus making the sABs to better resemble natural antibodies and improving the clone-representing potential of the library. Aiming for the library size $\leq 10^{10}$ unique CDR combinations can significantly improve the clone coverage and sampling power of the phage display.

As was stated above, theoretical size of the library depends on its design: the number of CDRs touched, the length range of the CDR loops and quality, and quantity of the codon-randomization events in each CDR. Following the natural antibody tendency favoring the highest variability and paratope involvement in L3 and H3 CDRs, most sAB libraries that have only H3 and L3 diversified and just one of the canonical natural sequences incorporated in place of each of other four CDRs, proved to be very efficient $[73,75,76]$; however, some high-quality libraries have all six CDRs diversified $[72,77,78]$. Surprisingly, the minimalist libraries, containing sequences of only two residues, Tyr and Ser, in their CDRs, were proven highly effective in generating specific antibodies against a wide array of antigens providing a rationale for high abundance of these two residues in the CDRs of the natural immune repertoire $[62,79]$. Due to the simpler design, these libraries are relatively easy to construct, and, due to the smaller theoretical size, they possess higher sampling power. Involvement of more of CDRs and CDR positions into deeper diversification, while producing an exponentially increasing number of possible variants, allows to build more enhanced and sterically extended paratopes with higher conformational diversity, thus, facilitating efficient recognition of various epitopes of different types of antigens.

As was mentioned above, natural antibody libraries have a huge advantage over any $\mathrm{SAB}$ library since they contain only expressible and stable CDR variants that have passed multiple control points of the immune system. In addition, chemical synthesis of CDRs is inherently compromised by synthetic errors, introducing all sorts of mutations that generate unwanted amino-acid substitutions and stop codons resulting in nonfunctional antibody clones $[72,77]$ To eliminate poorly expressed clones and non-productive frame shifts, a proofreading step, such as selection of ampicillin-resistant $\mathrm{sAB}-\beta$ lactamase genetic fusions, has been added as the final step of library construction [77].

Another important aspect defining functionality of the $\mathrm{SAB}$ phage display is a balance between the theoretical number of possible variants set by the design, and the number of unique phage clones achieved at a construction step, i.e., the library sampling power. Clone underrepresentation in a library can also be caused by clone- 
specific impediments, like slower replication or assembly rates, reducing or even eliminating the pool of most troubled variants. The higher-order diversification design may account for such astronomical calculated number of the unique variants that the realistically limited of manageable phage library variety of $10^{12}$ clones rationalized above would constitute only a microscopic fraction of the theoretical prospects. Due to this problem, more extensive and deeper diversification would not allow for selection of the ideal antibody variants, covered by the design but not even present during the phage panning, however, there would be a greater variety of the second- and third-best clones, suitable for the task. SAB phage libraries of this kind have produced a wide range of high-quality antibodies for a broad spectrum of antigens, although their theoretical variety is hugely under-sampled. The welldesigned $\mathrm{SAB}$ libraries have several distinct advantages, which include optimal variability, size, clone representation and density of the display, high sAB expression, solubility and stability, and ease of further engineering and optimization.

\section{THE KOSSLAB PIPELINE}

Synthetic-antibody library construction. The KossLab pipeline have been constructed based on the scaffold from a humanized Fab 4D5 Herceptin framework (here, Fab ${ }^{\mathrm{S}}$ ) engineered for high stability and efficient phage display. Combination of the mixed nucleotide and trinucleotide phosphoramidite based methods were used for synthesis of randomized DNA oligonucleotides that were next cloned into the Fab framework using Kunkel mutagenesis method [80].

In the library, limited amino acid diversity is introduced into all three HC CDRs ( $\mathrm{H} 1, \mathrm{H} 2$, and $\mathrm{H} 3)$, as well as the third CDR of LC: L3, while L1 and L2 have fixed canonical loops: SVSSA and SASSLYS, respectively. L3 length varies from four to six residues. In $\mathrm{H} 3$, the loop lengths range from 6 and 20 residues (sub-library A), 7 and 15 residues (sub-library B) or 6 and 17 residues (sublibraries $\mathrm{C}$ and $\mathrm{D})$. $\mathrm{H} 3$ design in the most complex sublibrary D (6 to 17 residues) was based on a tailored oligonucleotide synthesis strategy that biased the sequences in favor of $\mathrm{Y}, \mathrm{S}$ and $\mathrm{G}$ but allowed for 19 of the 20 genetically encoded amino acids (only $\mathrm{C}$ was excluded) and potentiated high level of diversity amongst the $\mathrm{H} 3$ loops in terms of both length and sequence. The pooled library consists of $10^{10}$ unique variants, huge under-sampling of the theoretical diversity (by more than 20 orders of magnitude) [62]. Extensive exploitation of the library over the years in hundreds of successful selections resulted in multitudes of high-affinity antibodies with dissociation constants in the sub-nanomolar to single-digit nanomolar range against a wide variety of protein antigens [81-100] confirming that this fully synthetic library with the limited diversification has essentially recapitulated capacity of the natural immune system.

Target immobilization and phage elution. Production and immobilization of the target-protein in an accessible and native functional state is the next critical step in the selection-project progress after obtaining high-quality phage-displayed SAB library. The original and still frequently used way of antigen immobilization for biopanning is passive protein adsorption on the activated plastic surfaces in random orientation through multiple nonspecific non-covalent interactions [101]. However, adsorption is usually accompanied by some degree of structural change of the antigen, and there is a possibility that the antibodies isolated against the passively adsorbed antigen may not recognize the free native antigen in solution. Nevertheless, passive immobilization is appealing due to simplicity of the method and frequent success of selections that yield clones that recognize and bind functional protein.

At present, the most common immobilization method avoiding adsorption-induced conformational changes of the antigen is based on the extremely tight biotin-streptavidin interactions [102] that are widely used in various research and biotechnology applications requiring tight and specific intermolecular interactions (detection and isolation of proteins, nucleic acids and lipids, protein purification, new-generation DNAsequencing, mass-spectrometry based proteomics and many others).

Protein antigen could be chemically conjugated with biotin [103] using commercially available biotinylation reagents targeting variety of specific functional groups or residues, including primary amines, sulfhydryls, carboxyls, and carbohydrates [104]. Chemical biotinylation can result in multiplicity of protein modification spots and masking or altering natural epitopes of the antigens by biotin moieties. Another, the least structure-disturbing way for biotin attachment, is through a genetic linkage of the antigen to Avi-tag, a peptide (GLNDIFEAQKIEWHE) specifically recognized and efficiently biotinylated by the biotin ligase BirA. BirA could modify Avi-tagged proteins in vitro, after purification [105], or in vivo [106], during expression in $E$. coli bearing BirA plasmid; in every case high-level of antigen biotinylation has been demonstrated (70-90\%). This modification level is sufficient for efficient capture of the antigen on the streptavidin-coated microplates or streptavidin-coupled magnetic beads followed by the library panning.

There are other affinity tags options for tethering proteins in a relatively uniform orientation with minimal disruption of native conformation [107] including metal ion[108, 109], antibody- [110], and protein-ligand capture technologies [111] that have been used for the target immobilization. Depending on the antigen immobilization technique, elution methods also vary widely. The most-common eluants are diluted solutions of $\mathrm{HCl}$ or 
Glycine (adjusted to $\mathrm{pH} 2-3$ ) that disrupt molecular interactions between the antibody displayed and the antigen immobilized (and the biotin-streptavidin complex too). Although there is almost no risk of eluting phage incompletely, the prolonged exposures to low $\mathrm{pH}$ could affect phage infectibility. If this becomes a problem, a gentle and highly specific alternative would be competitive elution with the antigen excess. This mostly releases the targetbound phage limiting selection of the non-specific clones [112, 113], but requires additional amounts of the purified antigen. The most common affinity-independent elution method entails insertion of a unique proteolytic site next to the affinity tag [114]. Cutting-off the affinity tag would trigger release of the target-bound phage exclusively, enhancing specificity of the selected phage clones comparably to the competitive elution. In addition, phage elution of any kind can be skipped, if no phage tittering is needed, instead, $E$. coli cells could be directly infected with the antigen-bound phage in selection wells or by addition of the phage pulled out on magnetic beads.

Although there are many other types and varieties of protein-binding chemistry, the exceptionally-high femtomolar affinity of a biotin-streptavidin pair makes this technique generally superior to others, since dissociative loss of the target during multiple washing steps at lower immobilization affinities could ultimately impede quality of the selection. In addition, the biotin-streptavidin binding, as many other receptor-ligand interactions, immune complexes included, is easy to eliminate at low $\mathrm{pH}$, which could be useful during the system set-up and testing.

Several modifiers and tags for target biotinylation have been applied in the immobilization protocols at KossLab pipeline at different periods and for specific antigens (i.e., natural non-recombinant proteins could be only biotinylated in a chemical reaction), including the SNAP-mediated biotinylation and immobilization that is discussed next.

SNAP-tagged targets: immobilization and specific proteolytic elution. Although the biotin-streptavidin binding is not covalent, it serves all intents and purposes in biopanning, since the binding is almost irreversible $\left(\mathrm{K}_{\mathrm{D}} \approx 10^{-15} \mathrm{M}\right)$. However, there are several popular novel protein tags that could be attached covalently to the specific chemical moieties of the insoluble matrix among multiple other useful soluble carriers. Such enzyme derivatives, as, HaloTag (Promega, USA) [115, 116], SNAPtag [117-119], and CLIP-tag [119, 120] (both - New England Biolabs) represent self-labelling tags that catalyze covalent attachment of the exogenously added specifically designed synthetic ligand. These systems have been exploited for years in vitro and in vivo for protein labeling, localization, and fluorescence, super-resolution, and electron microscopy imaging. HaloTag is a derivative of a bacterial enzyme haloalkane dehalogenase covalently linked through a reactive chloroalkane linker to a functional group of choice. Both SNAP-tag and CLIP-tag are engineered variants of the human DNA repair enzyme $\mathrm{O}(6)$-alkylguanine-DNA alkylotransferase that catalyzes transfer and attachment of the alkyl group via a thioether bond to the reactive cysteine of the enzyme. SNAP-tag has been engineered to reacts with $\mathrm{O}(6)$-benzylguanine, while CLIP-tag - with $\mathrm{O}(2)$-benzylcytosine derivatives. The discriminatory substrate binding and choice of the fluorescently labeled substrates, makes these two tags highly applicable for orthogonal labeling of proteins in living cells [120].

Availability of various other SNAP substrates, besides fluorescent, like SNAP-biotin and SNAP-capture magnetic beads (NEB), allowed us to develop and successfully apply several variants of the antigen-immobilization technique based on the SNAP-tagging of target proteins. In addition to the classic biotin-streptavidin based immobilization of the SNAP-biotinylated target, the novel way of direct covalent attachment onto the SNAP-capture magnetic beads has been tested. Covalent nature of the direct capture and extreme substrate specificity of the engineered SNAP-tag allowed for efficient immobilization of not only highly or partially purified targets but even immobilization from the crude lysates of the cells expressing SNAP-tagged proteins. This direct covalent capture could be hugely beneficial for the proteins with IMAC-incompatible characteristics or complicated purification protocols, despite the fact, that, in our hands, the SNAP-capture beads demonstrated reproducibly somewhat lower antigen-binding capacity and specificity for phage binding, compared to the best-performing Streptavidin-coupled magnetic beads (Dyno beads, Invitrogen, USA). Also, further improvement and optimization of the surface chemistry and ligand density of the SNAP-capture beads should eliminate this problem in future.

Biotinylation of the SNAP-tagged protein is a bimolecular reaction, simple, fast, completed within a short time, and irreversible that does not require any substantial excess of the SNAP-biotin reagent and, subsequently, is free of the purification step prior to the binding to streptavidin magnetic beads. We also have inserted a Thrombin-cleavage site between the tag and the antigen in the commercial SNAP-vector (New England Biolabs) to ensure fast and gentle elution of the enriched antigenbound phage from the magnetic beads without acidic treatment. Thrombin-cleavage site was chosen because it had the highest cleavage rate, compared to some other highly specific proteases [121], like TEV, PreScission, or $3 \mathrm{C}$ protease; their cleavage sites were introduced into the experimental SNAP-fusion proteins as well and the cleavage rates were tested.

Theoretically, cleavage should release only the target-specific phage, while the SNAP-tag-bound phage should remain attached to the beads, however, natural spontaneous phage dissociation could significantly con- 

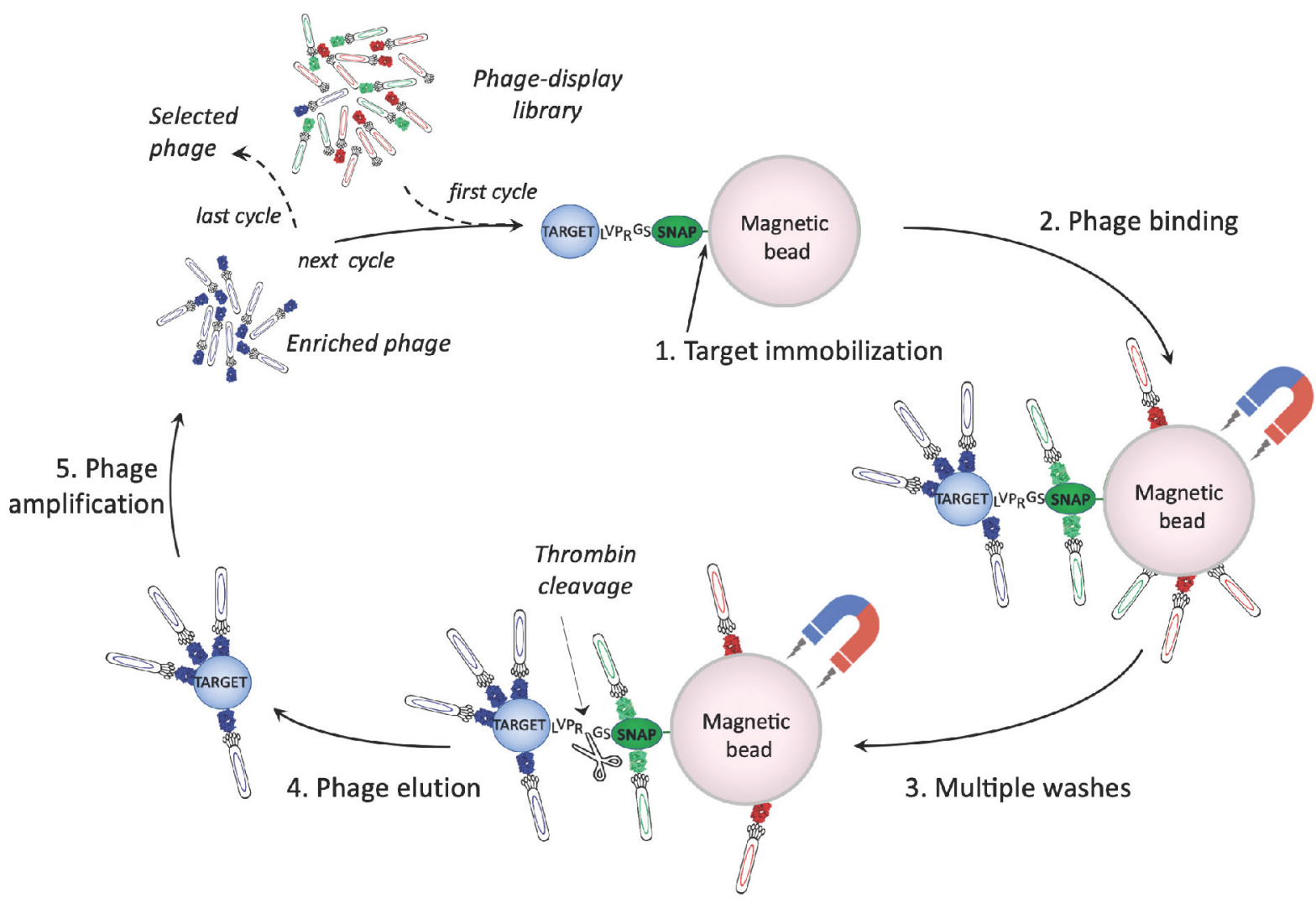

Fig. 2. Panning cycles of a phage-display library. The scheme represents principal steps of the cycle flow common in multiple protocols with highlighted specific details for the SNAP-tagged target immobilization and thrombin-mediated elution developed in the KossLab. 1) Target immobilization on magnetic beads. Immobilization of the SNAP-tagged target may be achieved by means of either direct covalent attachment to SNAP-capture beads or by biotinylation of SNAP-tagged target by SNAP-biotin prior to the Streptavidin-coupled bead binding. The LVPRGS thrombin-cleavage site in the linker between the target and SNAP-tag is shown. 2) Phage binding. Incubation of the phage-display library (at the first cycle) or enriched amplified phage (other cycles) with the bead-bound SNAP-target. 3) Multiple washes of the beads pulled out with a magnet to remove the unbound and weakly-bound phage. 4) Elution of the target-specific phages by thrombin cleavage of the linker; note that acid would elute all the bound phage non-specifically. 5) Amplification of the enriched phage by propagation in Escherichia coli aided by the helper phage. The new panning cycle starts as the amplified phage is added to the bead-immobilized target for binding. Normally, as the cycles progress, the amount of the target immobilized on the beads is decreased to benefit binding of the growing share of sABs with higher affinities. If improvement of the sAB dissociation rate is at question, the possible trick would be prolongation of the wash-time. Panning procedure could be manual, using magnets and magnetic racks, semi-automatic, on a magnetic particle processor (KingFisher, Thermo Fisher Scientific, USA), or fully automated - with the help of several robotic systems.

taminate the eluted phage. Therefore, to avoid phage binding to the immobilized SNAP-tag, a soluble SNAPtag competitor is added during the panning step. In addition, we found, that, like with other solubility-enhancing tag proteins (MBP, NusA, thioredoxin, GST, SUMO and Fh8 tag $[107,122])$, fusion to the SNAP-tag (182 amino acid-long, well-structured, highly soluble, and stable protein) can drastically improve stability, solubility, and production of the hard-to-express, poorly folded, and structurally unstable proteins.

The modified library-panning protocol developed in the KossLab for the SNAP-tagged targets (Fig. 2) has been successfully used, as demonstrated below, for $\mathrm{SAB}$ generation against dozens of targets, including viral proteins $[89,123]$ as well as for reciprocal maturation of the engineered-protein $\mathrm{G}$ and Fab-scaffold interface.

\section{SYNTHETIC ANTIBODIES. WHAT IS SPECIAL ABOUT THEM?}

sABs are superior to the naturally produced antibody in many special features and applications. To start with, $\mathrm{SAB}$ production is performed in vitro, free of demanding and expensive dependence on laboratory animals and can allow for isolation of very highly-selective antibody reagents confirmed to bind the native protein, or their certain conformations, or post-translationally modified forms. Also, sABs variety is not affected by such inherent limitations of the mammalian immune system as intolerance, or presence of immunodominant antigens, or clonal drift. Moreover, while natural monoclonal antibody reproduction requires continuous maintenance and storage of the hybridoma cell line, sAB clones can be indefi- 
nitely preserved in a form of frozen or lyophilized DNA. Due to the same AB scaffold used for cloning of all the variants, sABs are easy to sequence and reformat into a full antibody or expression vectors for production in bacterial or mammalian cells. This has driven development and validation of the high-throughput $\mathrm{SAB}$ expression platforms [124].

sABs could compete with monoclonal antibodies almost in any standard laboratory applications, like ELISA and related homogeneous and heterogeneous immunoassays, flow cytometry, immunostaining, immunoprecipitation, chromatin immunoprecipitation, and many others. However, methods, requiring recognition of SDS-denatured proteins (such as Western blotting) that are highly feasible for monoclonal antibody, could be problematic for $\mathrm{sAB}$. Unlike the most of naturalantibody CDRs that should recognize a short antigenic peptide (8-18 aa long) presented on the immune cell and thus are specific for linear epitopes readily accessible upon antigen denaturation, sABs are selected by binding to the native-state proteins. In the native form, many such linear epitopes are often hidden or interrupted, and outcompeted by the three-dimensional epitopes exposed and more potent for in vitro selection. Moreover, the wellstructured proteins with pronounced surface architecture and limited number of the defined low-energy states comprise the best $\mathrm{sAB}$ targets, while flexible, poorly folded, and unstable proteins are not appropriate targets for sABs selection but are as good as well-folded proteins for natural antibody production. Advantageously, in vitro selection potentiates unparalleled antibody customization, unachievable by natural production of immunoglobulins. By the means of precise control over the antigen composition and state under the highlymanipulatable panning conditions sABs can be tailored to: (i) target specific regions of the surface of a protein, (ii) recognize distinct conformational states of the antigen, (iii) induce desired conformational changes, and (iv) capture and stabilize transient states and multi-protein complexes [81]. These unique $\mathrm{sAB}$ capabilities are opening new possibilities for investigation of macromolecular structures and processes inaccessible to the traditional affinity-reagent technology.

SAB customization strategies. Different epitope targeting $s A B s$ and translational medicine. Like the natural process of antibody production, in vitro selection usually generates $\mathrm{SAB}$ variants recognizing antigen epitopes of high "immunogenicity". However, unlike natural immunogenicity, which is contingent also on the epitopespecific antibody progression through the controls of the immune system, the in vitro antigen epitope dominance depends, mostly, on the binding affinity of the sAB phage clone, and, to a lesser extend, on the share of the clone in the phage pool under the panning.

By binding to different epitopes of the protein, sABs can affect protein function as inhibitors or activators, promote or suppress ligand binding and homo- and hetero-protein interactions. SAB-based activators and inhibitors of definite immune checkpoints have proved their clinical efficacy as immunomodulatory therapeutics activating immune responds in tumorigenesis or reducing inflammation in autoimmunity. Besides the checkpoint blockade, similarly to the natural monoclonal antibodies, sABs could impact a variety of other areas, such as, allergy, transplantation, and T-cell immunotherapies.

The KossLab pipeline production also have confirmed an undeniable potential of sABs targeting different antigen determinants in translational medicine. For example, among the selected binders that modulate isocitrate dehydrogenase enzymatic activity, the explicit one has demonstrated ability to reactivate the enzyme mutant form associated with brain tumors [90]. "Activator drugs" of this kind could be the key remedy for many genetic disorders or malignant cell transformations caused by mutations disrupting protein function. Furthermore, a panel of sABs binding to different regions of paramyxovirus envelope glycoproteins and affecting different processes of the viral entry into the cell has been used to understand the steps in viral membrane fusion leading to acute respiratory infections [125].

Among the set of generated actin-filament pointedend binders, three sABs have demonstrated unique properties toward the actin-dynamic probing: one binder caps the pointed end, the second one crosslinks actin filaments, and the third severs actin filaments and promotes disassembly. This study may provide insights into the details of actin-filament rearrangements occurring in healthy and diseased human tissues, in innate and adaptive immune cells, during metastatic cancer and viral and bacterial infection [94].

A rapid and efficient screening to tailor phage-display for the selection of neutralizing antibody was set up in the KossLab for the Anthrax model. The high-affinity neutralizing sABs selected against edema toxin, an adenylate cyclase and a major mediator of anthrax pathogenesis, has demonstrated efficacy of the synthetic alternatives to the traditional antibody therapeutics: its potency to inhibit edema-toxin catalyzed cAMP production in human cells is comparable with that reported for the bestperforming monoclonal antibodies [126].

There are also $\mathrm{sAB}$ applications, where it is advantageous to deal with a variety of $\mathrm{SAB}$ specificities targeting non-redundant epitopes on the protein [127]. Although these are often obtained spontaneously and can be easily characterized by epitope-binning methods [128], sometimes, there is one major epitope prevailing in the selection. Then, the epitope-masking strategy directing the $\mathrm{sAB}$ binding on the protein away from the immunodominant hot spot could be implemented during the selection step. In this case, the sABs targeting the predominant protein epitope is pre-bound to the protein, thus, excluding the epitope from the competition for phage binding 
and allowing for selection of the $\mathrm{SAB}$ variants specific for the secondary epitopes.

In the KossLab, this trick has been efficiently applied in many instances, in particular, for generation of the sABs targeting non-redundant epitopes in two viral proteins, C-terminal domain of Ebola Zaire Nucleoprotein $\left(\right.$ EBOV NP ${ }^{\mathrm{CT}}$ ) and Zika methyltransferase (ZIKV MT), while developing a novel protein-complementation (PC)based wash-free immunoassay [123], relevant for pointof-care (POC) applications and described in a separate chapter below. And recently, the second $\mathrm{SAB}$ partner for SARS-CoV-2 detecting assay has been identified after masking the major epitope of the SARS-CoV-2 Spike protein receptor-binding domain by the predominant $\mathrm{sAB}$, that, in addition, has demonstrated an effective inhibition of the virus entry into the cell and can be used for the virus neutralization. Ability of this $\mathrm{SAB}$ pair to detect SARS-CoV-2 has been proven in the PC-based immunoassay, answering an urgent need for novel SARSCoV-2 POC diagnostics during the COVID-19 pandemic [85].

Conformational sABs. It is common, that the protein used as a selection target is not conformationally uniform and can represent a dynamic or static mix of low-energy states, sometimes caused by contaminating ligand molecules or certain metal ions. Under such conditions, generation of a conformationally-selective antibody recognizing just one of the antigen states is accidental. Alternatively, a specific conformational state of an antigen could be targeted already at the design conception. As an illustration, adding or omitting maltose at the panning step in the maltose-binding protein (MBP) system resulted in the selection of a cohort of three classes of highaffinity and specificity MBP binders: endosteric (binding to the maltose-binding pocket), allosteric (opposite to the maltose-binding pocket), and peristeric (close to the maltose-binding pocket) [88, 93]. These sABs stabilize MBP in different conformational states as has been revealed in the respective crystal structures. Respective modulations of the MBP ligand-binding affinity in competitive, allosteric, or peristeric manners, were used as probes to quantify energy contributions of the ligand binding to the conformational changes in proteins. Further development of this approach for more biological systems could in principle advance analysis of the energy landscapes of many systems including highly challenging regulatory proteins that control physiological responses to environmental changes.

$s A B s$ as tools for protein structure determination. As already mentioned, sABs represent indispensable tools for protein structure determination. They can be successfully used as fiducial markers for SP cryo-EM by adding mass $(50 \mathrm{kDa}$ for Fab) to the particle and assisting in its orientation [129]. Also, being easily crystallizable proteins with the known scaffold structure, sABs are widely used as crystallization chaperons that bind to a target of interest, enhance crystal packing, and provide high-quality phasing information. They have efficiently facilitated structure-determination of RNAs, RNA-protein complexes, protein complexes as well as individual proteins inherently recalcitrant to generate stable crystal lattices $[83,84,130]$. By driving a protein or its flexible parts to adopt and halt a uniform conformation, the conformation-specific sABs can enable crystallization of unstable, multi-conformational, multi-component or multi-subunit structures, membrane proteins and their complexes [81, 82, 98, 131].

Membrane proteins and nanodisc-based phage display. As it has been brought up by many investigators, membrane proteins continue to be among the most challenging targets in structural biology. The naturally programmed conformational changes in the membrane proteins are induced by external stimuli and are in the core of the signal transduction mechanism. Sophisticated interrelation between the structural and functional transformations underlying the transduction process is one of the most complicated though most exciting areas of the today's membrane-protein science. Membrane proteins are difficult to purify in a native form, and conditions matching their natural surroundings are hard to reproduce for crystallization purposes. Until recently, most $\mathrm{SAB}$ selection protocols targeting membrane protein have been performed in detergents, that are poor mimics of the native lipid environment. To produce sABs while resolving this problem, a novel approach, that combines the power of phage display with the benefits of embedding membrane protein targets in the lipid-filled nanodiscs has been developed in the KossLab [91, 132]. Nanodiscs, small (5-50 $\mathrm{nm}$ in diameter) discoidal particles consisting of lipids enclosed by the membrane scaffold proteins $[133,134]$ have been widely used in investigation of functional and structural properties of the membrane proteins as a sophisticated membrane mimetic system with precise control over their size and composition. For the purpose of application in phage display, the scaffold proteins of the nanodiscs are biotinylated enabling their pull-out by the magnetic beads. The nanodisc-based native-like lipid environment and the overall configuration of the system allow the partially imbedded target protein to adopt characteristic structural transitions, and the $\mathrm{sABs}$ to bind to these transient conformations. The novel approach developed in the KossLab yielded a rich pool of $\mathrm{sAB}$, that could be used as crystallization chaperones, fiducial markers for SP cryo-EM or energy probes for different conformational states of a number of membrane proteins, laying foundation for elucidation of the highresolution structures of the functionally relevant protein conformational states and understanding their dynamic interplay.

sABs as "universal" fiducial markers for SP cryoEM. SP cryo-EM has emerged over the past two decades as a powerful structural biology tool for challenging macro- 
molecular systems: it does not entail crystallization or phase determination problem and requires only small amounts of the experimental sample [129]. In 2017 the Nobel Prize in Chemistry was awarded jointly to Jacques Dubochet, Joachim Frank, and Richard Henderson "for developing cryo-electron microscopy for the high-resolution structure determination of biomolecules in solution" thus highlighting this technology as one of the greatest benefits to humankind [135]. Since SP cryo-EM success relies on the accurate assignment of particle location and orientation and their sufficient mass, only symmetric and heavy objects, like viruses, were appropriate for the method at the times of method conception [136, 137]. With the development of supportive new technologies, structures of many large protein complexes and oligomeric membrane proteins have been resolved to nearly atomic resolution by SP cryo-EM, the lower mass limit of the method has dropped to $50 \mathrm{kDa}[138,139]$. By increasing the particle mass and providing fiducial markers for particle alignments, sAbs significantly enable cryo-EM analysis and protein-structure determination [140, 141].

The antibody-based fiducial markers have considerably aided the membrane-protein structural studies in the field of G-protein coupled receptor (GPCRs) [142-144]. There are hundreds of different GPCRs belonging to 3 major classes encoded in human genome. They play a central physiological role in the regulation of cellular responses to a wide variety of stimuli in both health and disease and thus represent one of the largest types of surface receptors targeted by drugs. In the KossLab, sABs have been generated to the two major G-protein subclasses binding GPCRs: trimeric $\mathrm{G}_{\mathrm{i}}$ and $\mathrm{G}_{\mathrm{s}}$, as well as mini- $\mathrm{G}_{\mathrm{s}}$ with the goal to overcome specificity limitations of the fiducials tailored for a particular GCPRs. Epitope binning revealed that multiple distinct epitopes were targeted for each of trimeric G-protein, while some of the sABs cross-react between the trimeric $G_{i}$ and $G_{s}$, suggesting their universal application across the subclasses. Similarly, sABs were generated to a representative of another class of GPCR signaling partner, G-protein receptor kinase 1 , supporting the generalizability of the fiducial marker approach. EM data confirmed efficacy of the sABs as single and dual fiducials for multiple GPCR signaling complexes [87].

In addition, a universal $\mathrm{sAB}$-targeted tag system that eliminates the need for a specific antibody for each individual membrane protein under structural study has been developed. To that end, an engineered variant of the apocytochrome b562, $12 \mathrm{kDa}$ protein BRIL has been chosen as such a tag since it contains terminal helical extensions easily adjustable for the distortion-free seamless connection to $\alpha$-helices present either in the loops [145] or at the termini [146, 147] of the membrane proteins. Several sABs generated and matured by the customized phage display selections against BRIL gained sub-nanomolar affinities and unhindered BRIL binding in multiple fusion systems. Negative-stain TEM and cryoEM structures of several examples of BRIL-membrane protein chimera demonstrated effectiveness of the sAB-BRILL systems as universal fiducial markers [86]. Thus, the technology is advancing towards making the "universal" sABs for the whole classes of proteins enabling their crystallographic and SP-cryoEM studies and potentially forming the "off the shelf" line of enhancement reagents. These would eliminate the need to incorporate the challenge of an antibody-engineering into the workflow of protein-structure determination projects.

Tools like sAB-based crystallization chaperones and fiducial markers have drastically improved the level and quality of structural analyses. To further improve effectiveness of the $\mathrm{sABs}$ as structure-determination chaperons, a special phage display engineering strategy, including a heat-stress step for the selected clones, has been used to generate Fab scaffold variants, that significantly reduces inherent flexibility of the "elbow" regions, which link the constant and variable domains of the Fab, disordering its structure. The strategy was validated using the previously recalcitrant $\mathrm{Fab}$-antigen complexes: introduction of the engineered elbow region remarkably enhanced crystallization and diffraction resolution, while their high affinity and stability retained [148]. Also, sAB solubility, was addressed in the design of shotgun scanning libraries introducing aspartate as a negative design element at the antigen-binding site. The selected highaffinity variants featured a polar ring surrounding the paratope. This significantly enhanced $\mathrm{sAB}$ specificity and solubility, crucial for easily aggregating antibodies, while maintained its affinity to the antigen [149]. These universal improvements of the overall $\mathrm{sAB}$ rigidity and solubility have further shaped them for structural determination studies.

\section{ENGINEERED PROTEIN G AND ANTIBODY-SCAFFOLD VARIANTS}

Ig-binding proteins. Fortunately, nature has provided protein engineers not only with the $\mathrm{IgG}$ molecule as a framework for sABs but also with Ig-binding proteins enabling their isolation, detection, and assembly. Several species of infectious bacteria express multivalent Ig-binding proteins on their surface. Single domains from a number of almost identical entities comprising multidomain bacterial protein A (Staphylococcus aureus), protein G (Streptococcus species C and G), and protein L (Peptostreptococcus magnus) have been characterized in detail both biochemically and structurally [150]. Each of these proteins has a different antibody binding profile in terms of the portion of the antibody that is recognized and the species and type of antibodies it binds. Protein A has greater affinity for the rabbit, pig, dog, and cat $\operatorname{IgG}$ 
whereas protein $\mathrm{G}$ has greater affinity for the mouse and human IgG. In addition to the predominant binding of both proteins $\mathrm{A}$ and $\mathrm{G}$ to the interface of $\mathrm{CH} 2-\mathrm{CH} 3$ heavy chains in the $\mathrm{Fc}$ (fragment crystallizable), they also bind to the Fab: Protein A - to VH, while protein G binds simultaneously, but very weakly, to $\mathrm{CH} 1$, a highly conserved domain across many isotypes and species, and CL kappa. Protein L only binds to VL kappa of the Fab part and exclusively [151, 152].

Proteins A, G, and L have a scope of biochemical, biotechnological, and medical applications and are widely used in antibody purification and test methods like immunoprecipitation, ELISA, and Western blotting [153]. The "universal" recombinant fusion protein A/G comprised of four domains of protein A and two domains of protein $\mathrm{G}$ demonstrates additive properties of the two proteins and captures antibodies from the combined spectra of species and isotypes [154, 155].

Recent engineering efforts in applied immunological and biochemical research have led to production of the synthetic ligands mimicking protein $\mathrm{A}$ and $\mathrm{L}$ (peptides, engineered protein domains, and designed artificial molecules). These mimetics can replace the originals for purification of antibodies, while surmounting some drawbacks such as high cost, low binding capacity, limited life cycles and so on [156].

An engineered GA1 variant. Protein $\mathrm{G}$ is used for $\mathrm{IgG}$ purification by the virtue of its affinity to the Fc portion of the molecule $\left(\mathrm{K}_{\mathrm{D}} \sim 10 \mathrm{nM}\right)$, while its binding to the Fab CH and CL is pretty weak $\left(\mathrm{K}_{\mathrm{D}} \sim 3 \mu \mathrm{M}\right)$. The $4 \mathrm{D} 5$ Herceptin Fab scaffold $\left(\mathrm{Fab}^{\mathrm{S}}\right)$ of the KossLab pipeline containing E123S mutation in the Fab CL has been used for affinity maturation of protein $\mathrm{G}$ (a 65 aa-long $\mathrm{C} 2$ domain) [157]. The affinity maturation design involved soft randomization of the two points of contact with the $\mathrm{Fab}^{\mathrm{S}}$ scaffold: one, residues 15-24, involved in the formation of antiparallel $\beta$-strands with Fab $\mathrm{CH}$ and second, residues 37-43, interacting with the short non-conserved $\beta$-helical region connecting $\beta$-strands in CL. The matured variant GA1 demonstrated the highest improvement in the $\mathrm{Fab}^{\mathrm{S}}$ binding affinity, mostly due to substitutions of NDNG in the positions 40-43 for YVHE. In the crystal structure of GA1-Fab ${ }^{\mathrm{S}}$ complex, these residues form a structural helical cap in the GAl interdigitating with the CL $\alpha$-helical residues SQLKS improving the interface complementarity.

An engineered FAB $^{\mathrm{LRT}}$ scaffold variant. Compared to the wild-type protein $\mathrm{G}, \mathrm{GA} 1$ demonstrates a significant affinity boost in binding $\mathrm{Fab}^{\mathrm{S}}\left(\mathrm{K}_{\mathrm{D}} \sim 50 \mathrm{nM}\right)$ - adequate for applications that involve genetically linked GA1 strings to make multi-valent Fab assemblages [157]. However, binding is still characterized by fast dissociation kinetics that is not optimal for the desired non-equilibrium applications. To further improve affinity and dissociation kinetics of the GA1-Fab complex, we undertook a reciprocal phage display approach: $\mathrm{Fab}^{\mathrm{S}}$ scaffold was affinity matured against GA1 [123]. The library design was focusing on the residues 123-127 (SQLKS) of CL. Kunkle mutagenesis using NNK/NNT randomization yielded $\sim 10^{10}$ clones with theoretical diversity of $\sim 1.7 \times 10^{7}$ unique codon variants (Fig. 3). Several selected variants demonstrated significantly increased binding affinity and

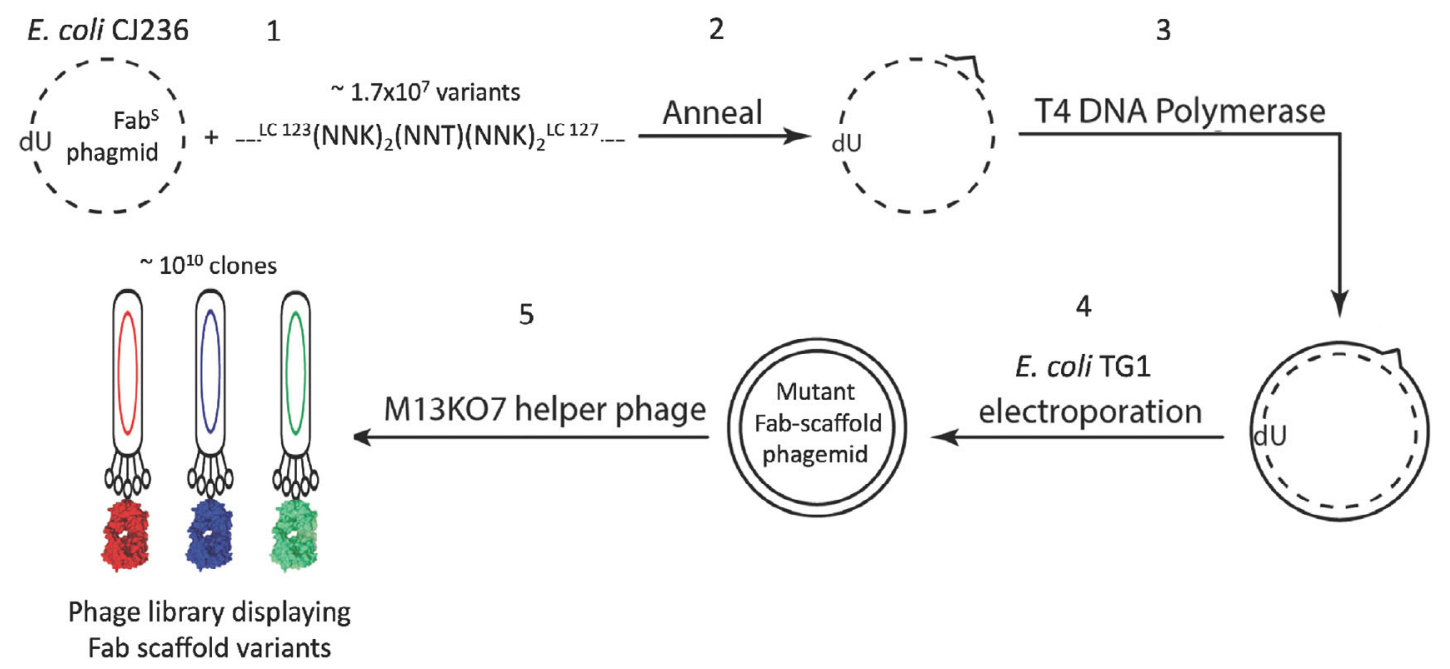

Fig. 3. Construction of the phage-display library for Fab scaffold GA1-binding affinity maturation. Schematic representation of the degenerate-codon based randomization by Kunkel mutagenesis: a random $\mathrm{Fab}^{\mathrm{S}}$-encoding phagemid containing dU substitutions for $\mathrm{T}$ was isolated from CJ236 E. coli strain (1), annealed with a synthetic DNA oligonucleotide comprised of a randomization sequence: ${ }_{\mathrm{LC}}^{123}(\mathrm{NNK})_{2}(\mathrm{NNT})(\mathrm{NNK})_{2}^{\mathrm{LC}}{ }^{127}$, flanked by $15 \mathrm{nt}$ of the wild-type overhangs (2) used to prime the DNA synthesis by T4 DNA polymerase; the synthesized dU/T duplex phagemid molecule was transformed into the TG1 E. coli strain aiming for destruction of the wild-type dU-containing strand and efficient replication of the mutant T-containing strand (4). The following superinfection with M13 KO7 helper phage resulted in the mutant phage propagation (5). 
reduced dissociation rate. The best selected Lc variant with 500-fold improved affinity to GA1 contained a serendipitous two amino acid deletion, which may have occurred during the synthesis of randomizing DNA oligonucleotides. Replacement of the original SQLKS sequence of Fab ${ }^{\mathrm{S}}$ with $\Delta \Delta \mathrm{LRT}\left(\mathrm{Fab}^{\mathrm{LRT}}\right)$ resulted in the $\mathrm{K}_{\mathrm{d}}$ of $\sim 100 \mathrm{pM}$, slow dissociation rate $\left(\sim 2.4 \times 10^{-4} \mathrm{~s}^{-1}\right)$ and did not affect Fab stability or expression.

The key structural basis underlying this ultra-high affinity of the Fab ${ }^{\mathrm{LRT}}$ was revealed in a crystal structure solved for the GA1-Fab ${ }^{\mathrm{LRT}}$ complex: a significant deletion-induced rearrangement and extension of the interface has packed the guanidinium group of $\operatorname{Arg} 124$ (replacing Lys126 in $\mathrm{Fab}^{\mathrm{S}}$ ) against the aromatic ring of Tyr40 of GA1 in a cation $-\pi$ interaction, while providing H-bonding with the Tyr40 carbonyl via the secondary amine in $\varepsilon$ position of $\operatorname{Arg} 124$ [123].

\section{A NOVEL PLUG-AND-PLAY PLATFORM}

The ultra-high GA1 binding affinity and extremely low dissociation rate of the $\mathrm{Fab}^{\mathrm{LRT}}$ encouraged us to develop a multivalent and multi-specific platform based on the GA1 module that could be easily modified just by exchange of the Fab component. Although the $\mathrm{Fab}^{\mathrm{LRT}}$-GA1 interaction is not covalent, no exchange between the partners, which could compromise the performance of such a platform, has been detected within the timeframe of experiments.

There is a great variety of possible functionally relevant GA1 genetic fusions, allowing the researcher to design highly customized affinity reagents that can be assembled in a wide scope of different formats in a straightforward way (Fig. 4a). The simplest example is being a string of genetically linked GA1 modules (Fig. 4b) for binding multiple, same or different-specificity, Fab ${ }^{\text {LRT }}$ molecules for the avidity boost or "randomized" multispecificity, respectively.

GA1 could be genetically coupled with the enzymes and protein tags for antigen detection by means of $\mathrm{Fab}^{\mathrm{LRT}}$ (Fig. 4c): we have successfully applied GA1 fusions to $\beta$ lactamase (with a fluorogenic substrate) or SNAP-tag (modified with a fluorescent label) to be paired with the interchangeable $\mathrm{Fab}^{\mathrm{LRT}}$ of a variety of specificities for routine antigen detection (ELISA, CFC) and imaging purposes. A novel wash-free $\beta$-lactamase complementation-based detection assay (Fig. 4d) has been developed by fusing GA1 to two split $\beta$-lactamase complementation fragments [158] (details of this work are discussed in the next chapter). Also, linking of GA1 to the IgG Fc fragment replacing Fab, resulted in the IgG mimetic (Fig. 4e) with the interchangeable $\mathrm{Fab}^{\mathrm{LRT}}$ specificity that could be utilized in place of multiple IgGs in the Fc-mediated processes. In addition, the GA1 fusions to the transmembrane domains (TMDs) of cell receptors made in the endoplasmic reticulum, anchors the exchangeable Fab component to the eukaryotic cell surface, thus, enabling investigation of the cell-cell signaling and interaction, and many other applications.

It turned out that the Fab-binding affinity maturation has been beneficial for GA1 in other aspects as well: it significantly reduced Fc binding and practically abolished GA1 affinity to all natural Fabs tested, including human kappa $\left(\mathrm{Fab}^{\mathrm{H}}\right)$ - the parental to $\mathrm{Fab}^{\mathrm{S}}$ [123]. This made the GA1-Fab ${ }^{\mathrm{LRT}}$ interactions insensitive to the presence of endogenous IgGs, which are very likely in many samples as a background - an essential detail for an experimental platform. High specificity and orthogonal nature of the GA1-Fab ${ }^{\text {LRT }}$ binding also allowed us to genetically connect a second specificity to the GA1 module in a form of $\mathrm{Fab}^{\mathrm{H}}$, or $\mathrm{scFv}$, without being concerned of their possible interaction and interference with the $\mathrm{Fab}^{\mathrm{LRT}}$ binding. The resulting bi-Fabs, functionally mimicking the bi-specific T-cell engagers (BiTEs), very efficient immunotherapeutics, have the advantage of one easily interchangeable specificity and are discussed in more details below. Fab ${ }^{\mathrm{LRT}}, \mathrm{Fab}^{\mathrm{H}}$, and scFvs containing and proximity-sensitive Fab ${ }^{\mathrm{LRT}}$ and split-scFv GA1-complexes represent two of many possible tri-specific formats (Fig. 4f). In addition, it is important to note, that the control over the linker length in the GA1 fusions could be an essential variable for applications in the systems with specific dimensional or steric demands.

A novel $\beta$-lactamase complementation-based assay. As mentioned above, we have developed a wash-free antigen-detection system based on the GA1 module fusions in a protein-fragment complementation format, widely used for identification and studying of protein-protein interactions. It is comprised of two fusions of GA1 to two complementary $\beta$-lactamase fragments (BLFs) individually pre-bound to the two Fab ${ }^{\mathrm{LRT}}$ component targeting non-redundant epitopes of the antigen of choice. When the fusions bind independently to the non-overlapping epitopes on the antigen by means of $\mathrm{Fab}^{\mathrm{LRT}}$ component, proximity of the BLFs attained within the immune complex should allow them to reassociate into the active enzyme, detectable with a fluorogenic substrate (Fig. 4d). Success of complementation and enzyme reactivation depend to a great extent on the appropriateness between the length of fusion linkers and the distance between the antigen epitopes targeted by Fabs.

The recent world threats caused by severe viral infections motivated us to choose Ebola and Zika virus proteins (EBOV NT ${ }^{\mathrm{CT}}$ and MT ZIKV, respectively) as antigens to be detected in the system and used initially for generation of the high-affinity sABs by phage-display selections reformatted next into the Fab ${ }^{\mathrm{LRT}}$ scaffold. The independent mode of antigen binding by the Fab pairs was confirmed by SPR. The 30 aa-long linker $(\sim 100 \AA$ stretched) used in all GA1 fusions turned out to be sufficient for successful complementation; $\beta$-lactamase activ- 
a

GA1 genetic-fusion variants

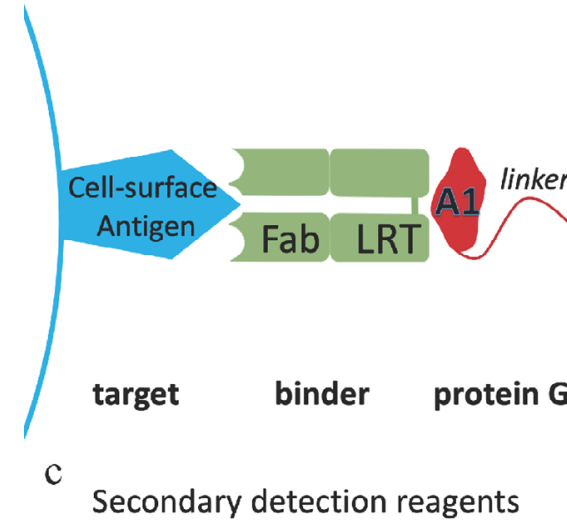

GA1

Tag/fuorescence

Enzyme/split

scFV/split

$\mathrm{FC}$

TMD

$\mathrm{Fab}^{\mathrm{H}}$

effector

d

Split-BL detection assay
GA1 strings (mono- to deca-mers)

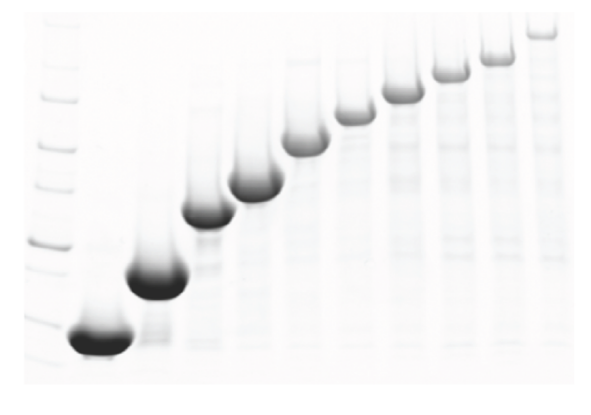

e Fc fusions (IgG mimic)
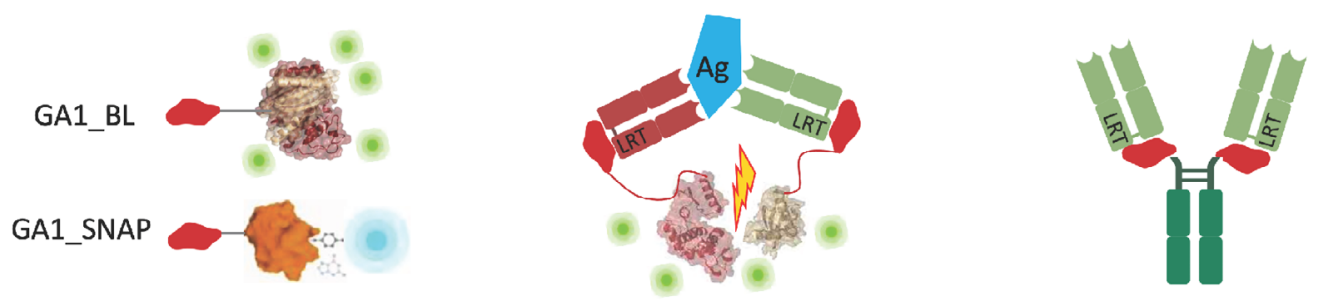

f

Bi-specific binders and tri-specific binders
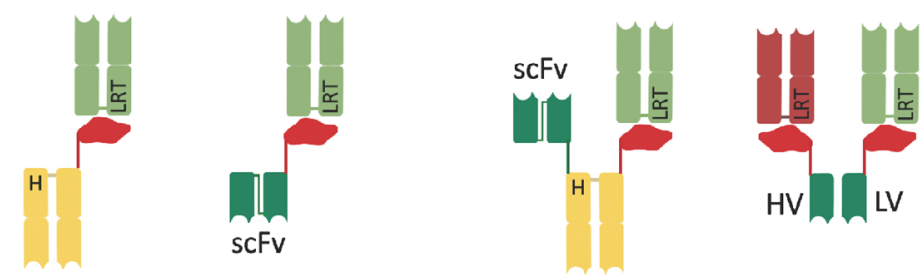

bi-Fab

Fig. 4. GA1-based plug-and-play platforms. Schematic representation of the target-directed Fab ${ }^{\mathrm{LRT}}$ delivering GA1-fused effector, and some effector variant (a): GA1 modules to build multimeric strings for avidity enhancement (b); enzyme- or fluorescent tags for protein detection (c), split enzymes for protein complementation detection assays (d); GA1 fusions to Fc, mimicking IgG (e); GA1 fusions with Fab ${ }^{\mathrm{H}}$ (bi-Fab) or scFv for BiTE mimetics and some possible tri-specific binders (f). Change of only the Fab ${ }^{\mathrm{LRT}}$ component in the system will redirect its specificity.

ity was readily detected by a fluorescent signal in the reactions containing viral antigens with antigen-appropriate $\mathrm{Fab}^{\mathrm{LRT}}$ pairs and complementary GA1-BLF [123].

This wash-free sandwich antigen-detection system has been also applied for SARS-CoV-2 detection using a pair of $\mathrm{Fab}^{\mathrm{LRT}}$ targeting two non-overlapping epitopes of the Spike RBD. The detection limit of the systems $(\sim 10 \mathrm{nM})$ falls within the standard range for a sandwich antigen-detection immunoassay, like ELISA. Together with the simple and fast non-wash procedure, reproducible quantitative results, and detected-antigen adjustability, easily achievable by $\mathrm{Fab}^{\mathrm{LRT}}$ pair exchange, this makes the protein-complementation GA1-based assay a suitable candidate for POC applications; in addition, it was shown, that its components can be freezedried and fully reactivated after rehydration [85].
The strong assay performance confirmed high potential of GA1 as an effective non-covalent bond between the BLFs and $\mathrm{Fab}^{\mathrm{LRT}}$ of any specificity, thus, laying the basis for numerous plug-and-play opportunities.

A novel plug-and-play BI-Fab format. Our next endeavor undertaken was to apply the ultra-high affinity GA1-Fab ${ }^{\text {LRT }}$ platform for building bi-Fabs complexes mimicking structurally and, hopefully, functionally the bi-specific T-cell engagers (BiTEs), with an advantage of one varying specificity providing by the interchangeable Fab component in a plug-and-play manner.

Classical BiTEs represent engineered fusion molecules, consisting of two different scFvs of particular specificities - one, binding to T-cells via the CD3 component of the T-cell receptor complex, and the other - to a cancer cell via a tumor-specific molecule [27]. This engage- 
ment leads to the T-cell dependent death of the cancer cell.

The principle of two-molecule design of bi-Fabs exploits the GA1 module as a reliable non-covalent fixative for Fab ${ }^{\mathrm{LRT}}$ already experimentally approved in this capacity in the plug-and-play detection assay discussed above. Since GA1 orthogonal binding demonstrates no measurable binding to $\mathrm{Fab}^{\mathrm{H}}$ scaffold, it allows to genetically fuse $\mathrm{Fab}^{\mathrm{H}}$ to GA1 through a flexible linker without affecting the GA1-binding when Fab ${ }^{\mathrm{LRT}}$ is added to the fusion, forming a bi-Fab - a stable association of two distinct antigen-binding specificities [123].

To mimic the BiTE design in the bi-Fab format, we choose two antigen targets: (i) T-cell specific CD3 receptor commonly used in the BiTE therapy and as a specific cell surface marker, and (ii) HER2 receptor, highly overexpressed on the cell surface in many cancer cells such as breast-cancer cell lines, including SKBR3. To that end, three well-characterized antibodies were chosen: the already tested in the BiTE format humanized $\alpha-C D 3$ antibodies, OKT 3 or UCHT1; and $\alpha$-HER 2 trastuzumab, highly therapeutic anti-cancer antibody. To construct bi-
Fabs in either "polarities", each antibody was reformatted in both $\mathrm{Fab}^{\mathrm{H}}$ and $\mathrm{Fab}^{\mathrm{LRT}}$ scaffolds and all three resultant $\mathrm{Fab}^{\mathrm{H}}$ variants were fused to $\mathrm{GA} 1$ at their $\mathrm{Hc} \mathrm{C}$-termini via a 13 aa-long GS linker. The bi-Fabs were assembled combining the CD3 or HER2 specificities reciprocally as either $\mathrm{Fab}^{\mathrm{H}}$-GA1 fusion or Fab ${ }^{\mathrm{LRT}}$ (Fig. 5).

All the bi-Fab combinations showed efficient T-cell engagement activity, similar to the activity of the covalently linked BiTE, as measured in the PBMC-SKBR3 co-cultures by three readouts: (i) activity of the cytoplasmic enzyme, lactate dehydrogenase, released into the medium upon cell lysis caused by activation of cytotoxic T-cells; (ii) interleukin IL2, and (iii) interferon $\gamma$ produced by T-helper cells. As expected, functionality of the bi-Fabs was absolutely dependent upon the genetic fusion of GA1 to $\mathrm{Fab}^{\mathrm{H}}$, as no detectable activity was observed when all the individual components $\left(\mathrm{Fab}^{\mathrm{H}}, \mathrm{Fab}^{\mathrm{LRT}}, \mathrm{GA} 1\right)$ were added as three separate unlinked entities [123].

Given the ease of interchanging $\mathrm{Fab}^{\mathrm{LRT}}$ in the biFabs, we envision the following possible advances of the GA1-based plug-and-play BiTE mimetics. A highthroughput platform can be developed to profile bi-Fabs

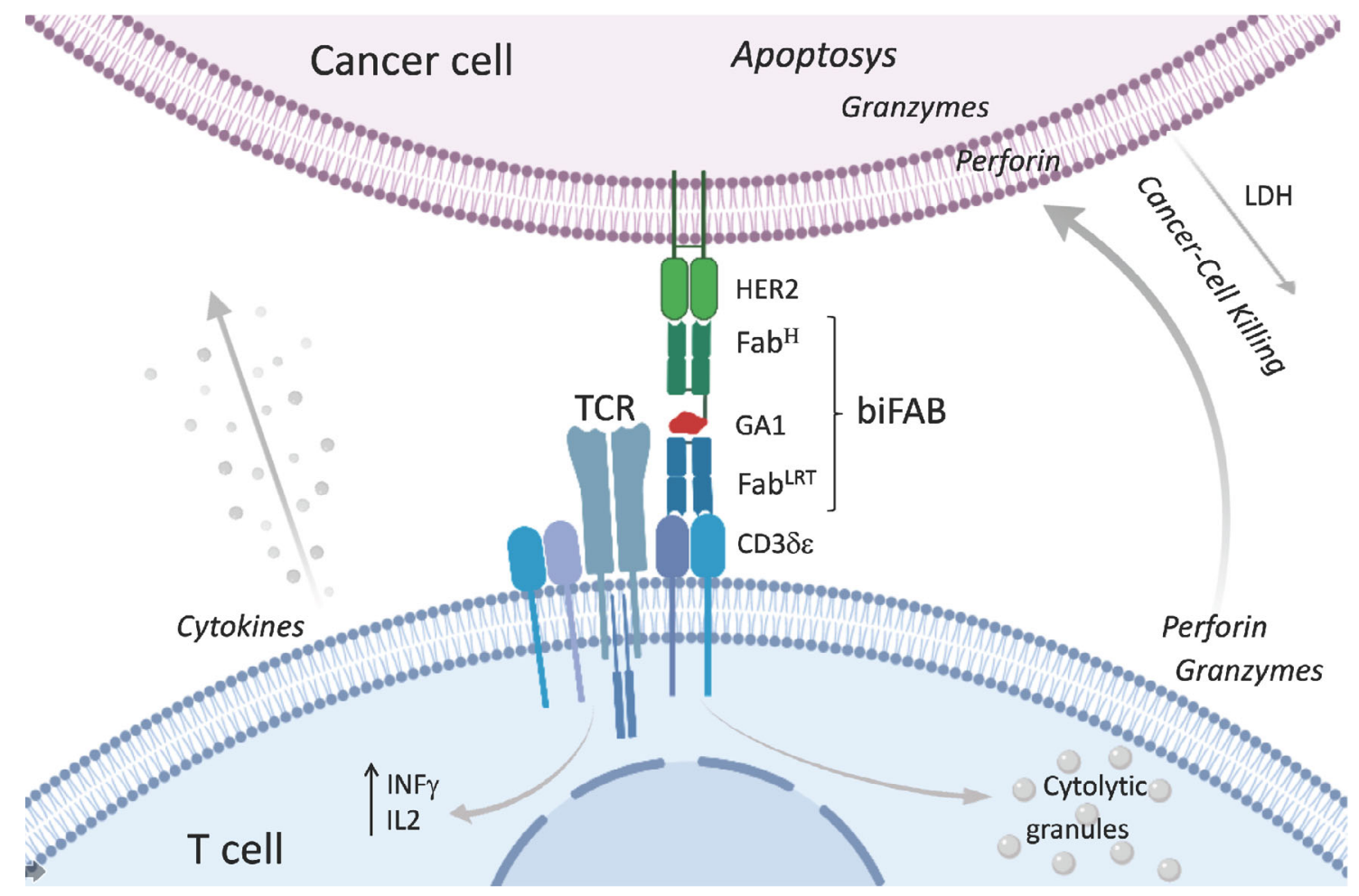

Fig. 5. Schematic representation of T-cell engagement in cytolytic synapse with cancer cell expressing HER2 receptor by means of bi-Fab inter-cellular bridging: it binds HER2 receptor with $\mathrm{Fab}^{\mathrm{H}}$, genetically fused to GA1, while $\mathrm{Fab}^{\mathrm{LRT}}$, non-covalently attached to GA1, binds to $\mathrm{CD} 3 \delta \varepsilon$ co-receptor of T-cell specific receptor (TCR). Activation of the CD8 cytotoxic T-cell involves cytolytic granule fusion and release directed toward the cancer cell, while the activated CD4 helper T-cells increase production and secretion of cytokines interferon $\gamma$ and IL2, activating cytokine production, cytolytic effect, and proliferation of peripheral blood immune cells. Lysis of the attached cancer cell is caused by the membrane perforation by perforin, and subsequent programmed cell death induced by granzymes, entering through the perforin pores into the cancer cell cytoplasm. Compilation of the T-cell activation effects is shown. Bi-Fab is colored as following: GA1 is shown in red; fused to it, $\mathrm{Fab}^{\mathrm{H}}$ (specific for HER2 receptor of cancer cell) - in green, and Fab ${ }^{\mathrm{LRT}}$, specific to CD3 - in blue. Two different CD3-specific $\mathrm{Fab}^{\mathrm{LRT}}$, derivatives of OKT3 and UCHT1 antibodies, were interchangeably used with trastuzumab-derived $\mathrm{Fab}^{\mathrm{H}}$ fused to GA1. 
targeting many different cancer-specific cell-surface markers through the Fab ${ }^{\mathrm{LRT}}$ assortment. Then, the Fab ${ }^{\mathrm{LRT}}$ variety could target any number of surface antigens on a certain type of cancer cells, amplifying therapeutic effect. In addition, as in other GA1-fusion applications, the linker length could be easily adjusted tailoring the bi-Fab for the particular antigen or even antigen epitope. Multiple GA1 modalities could be also included into the design to exploit possible avidity effects in the resulting multi-valent bi-specific formats.

\section{PERSPECTIVES}

Protein engineering is now a mature field of protein science. While the ability to clone, express, and purify proteins is well established and is incorporated into the most standard operating procedures in the research laboratories, the field will continue to evolve as new technologies that build on those described here are brought into practice. One might argue that protein engineering has been practiced for hundreds of years through genetic selections. However, attempts to understand molecular basis of the phenotypic alterations and to rationally design them have only become possible through the relatively recent process involving integration of the protein structure information. An important aspect of protein engineering is that it has both basic and applied research applications. Thus, we can work on projects that build our basic understanding of the molecular basis of biological systems, while at the same time, produce molecules that are beneficial to health care and to society in general.

Acknowledgments. The author is deeply grateful to Tony Kossiakoff for critical reading and fruitful discussions of the review and to Erna Davydova for technical help.

Ethics declarations. The author declares no conflicts of interest. This article does not contain studies with human participants or animals performed by the author.

\section{REFERENCES}

1. Paria, D., and Venugopalan, P. L. (2019) Controlling evolution: The Nobel Prize in chemistry 2018, IEEE Pulse, 10, 12-16, doi: 10.1109/MPULS.2019.2922566.

2. Samish, I. (2017) Achievements and challenges in computational protein design, Methods Mol. Biol., 1529, 21-94, doi: 10.1007/978-1-4939-6637-0_2.

3. Korendovych, I. V. (2018) Rational and semirational protein design, Methods Mol. Biol., 1685, 15-23, doi: 10.1007/ 978-1-4939-7366-8_2.

4. You, L., and Arnold, F. H. (1996) Directed evolution of subtilisin E in Bacillus subtilis to enhance total activity in aqueous dimethylformamide, Protein Eng., 9, 77-83, doi: 10.1093/protein/9.1.77.
5. Shao, Z., and Arnold, F. H. (1996) Engineering new functions and altering existing functions, Curr. Opin. Struct. Biol., 6, 513-518, doi: 10.1016/S0959-440X(96)80117-5.

6. Moore, J. C., and Arnold, F. H. (1996) Directed evolution of a para-nitrobenzyl esterase for aqueous-organic solvents, Nat. Biotechnol., 14, 458-467, doi: 10.1038/nbt0496-458.

7. Zhao, H., Li, Y., and Arnold, F. H. (1996) Strategy for the directed evolution of a peptide ligase, Ann. N.Y. Acad. Sci., 799, 1-5, doi: 10.1111/j.1749-6632.1996.tb33169.x.

8. Molina-Espeja, P., Viña-Gonzalez, J., Gomez-Fernandez, B. J., Martin-Diaz, J., Garcia-Ruiz, E., et al. (2016) Beyond the outer limits of nature by directed evolution, Biotechnol. Adv., 34, 754-767, doi: 10.1016/j.biotechadv. 2016.03.008.

9. Smith, G. P. (1985) Filamentous fusion phage: Novel expression vectors that display cloned antigens on the virion surface, Science, 228, 1315-1317, doi: 10.1126/science. 4001944.

10. Parmley, S. F., and Smith, G. P. (1988) Antibody-selectable filamentous fd phage vectors: affinity purification of target genes, Gene, 73, 305-318, doi: 10.1016/03781119(88)90495-7.

11. Doorbar, J., and Winter, G. (1994) Isolation of a peptide antagonist to the thrombin receptor using phage display, J. Mol. Biol., 244, 361-369, doi: 10.1006/jmbi.1994.1736.

12. Winter, G., Griffiths, A. D., Hawkins, R. E., and Hoogenboom, H. R. (1994) Making antibodies by phage display technology, Annu. Rev. Immunol., 12, 433-455, doi: 10.1146/annurev.iy.12.040194.002245.

13. Clackson, T., Hoogenboom, H. R., Griffiths, A. D., and Winter, G. (1991) Making antibody fragments using phage display libraries, Nature, 352, 624-628, doi: 10.1038/ $352624 \mathrm{a} 0$.

14. Marks, J. D., Ouwehand, W. H., Bye, J. M., Finnern, R., Gorick, B. D., et al. (1993) Human antibody fragments specific for human blood group antigens from a phage display library, Biotechnology $(N Y), \mathbf{1 1}, 1145-1149$, doi: 10.1038/nbt1093-1145.

15. Smith, G. P., and Petrenko, V. A. (1997) Phage display, Chem. Rev., 97, 391-410, doi: 10.1021/cr960065d.

16. Newton-Northup, J. R., Dickerson, M. T., Kumar, S. R., Smith, G. P., Quinn, T. P., et al. (2014) In vivo bacteriophage peptide display to tailor pharmacokinetics of biological nanoparticles, Mol. Imaging Biol., 16, 854-864, doi: 10.1007/s11307-014-0762-z.

17. Petrenko, V. A., and Smith, G. P. (2000) Phages from landscape libraries as substitute antibodies, Protein Eng., 13, 589-592, doi: 10.1093/protein/13.8.589.

18. Liang, C. T., Roscow, O. M. A., and Zhang, W. (2021) Recent developments in engineering protein-protein interactions using phage display, Protein Eng. Des. Sel., 34, gzab014, doi: 10.1093/protein/gzab014.

19. Nagano, K., and Tsutsumi, Y. (2021) Phage display technology as a powerful platform for antibody drug discovery, Viruses, 13, 178, doi: 10.3390/v13020178.

20. Reader, R. H., Workman, R. G., Maddison, B. C., and Gough, K. C. (2019) Advances in the production and batch reformatting of phage antibody libraries, Mol. Biotechnol., 61, 801-815, doi: 10.1007/s12033-019-00207-0.

21. Sokullu, E., Gauthier, M. S., and Coulombe, B. (2021) Discovery of antivirals using phage display, Viruses, 13, 1120, doi: 10.3390/v13061120. 
22. Almagro, J. C., Pedraza-Escalona, M., Arrieta, H. I., and Perez-Tapia, S. M. (2019) Phage display libraries for antibody therapeutic discovery and development, Antibodies (Basel), 8, 44, doi: 10.3390/antib8030044.

23. Gillespie, J. W., Wei, L., and Petrenko, V. A. (2016) Selection of lung cancer-specific landscape phage for targeted drug delivery, Comb. Chem. High Throughput Screen., 19, 412-422, doi: 10.2174/1386207319666160420141024.

24. McCafferty, J., Griffiths, A. D., Winter, G., and Chiswell, D. J. (1990) Phage antibodies: filamentous phage displaying antibody variable domains, Nature, 348, 552-554, doi: 10.1038/348552a0.

25. Dean, A. Q., Luo, S., Twomey, J. D., and Zhang, B. (2021) Targeting cancer with antibody-drug conjugates: Promises and challenges, $m A b s, 13,1951427$, doi: 10.1080/ 19420862.2021.1951427.

26. Einsele, H., Borghaei, H., Orlowski, R. Z., Subklewe, M., Roboz, G. J., et al. (2020) The BiTE (bispecific T-cell engager) platform: Development and future potential of a targeted immuno-oncology therapy across tumor types, Cancer, 126, 3192-3201, doi: 10.1002/cncr.32909.

27. Baeuerle, P. A., and Reinhardt, C. (2009) Bispecific T-cell engaging antibodies for cancer therapy, Cancer Res., 69, 4941-4944, doi: 10.1158/0008-5472.CAN-09-0547.

28. Justiz Vaillant, A. A., Nessel, T. A., and Zito, P. M. (2021) Immunotherapy, in StatPearls, Treasure Island (FL), StatPearls Publishing.

29. Derebery, M. J., and Christopher, L. (2021) Allergy, immunotherapy, alternative treatments for dizziness, Otolaryngol. Clin. North Am., 54, 1057-1068, doi: 10.1016/ j.otc.2021.05.020.

30. Suryadevara, C. M., Gedeon, P. C., Sanchez-Perez, L., Verla, T., Alvarez-Breckenridge, C., et al. (2015) Are BiTEs the "missing link" in cancer therapy? Oncoimmunology, 4, e1008339, doi: 10.1080/2162402X.2015.1008339.

31. Allen, C., Zeidan, A. M., and Bewersdorf, J. P. (2021) BiTEs, DARTS, BiKEs and TriKEs-are antibody based therapies changing the future treatment of AML? Life (Basel), 11, 465, doi: 10.3390/life11060465.

32. Shim, H. (2017) Antibody phage display, Adv. Exp. Med. Biol., 1053, 21-34, doi: 10.1007/978-3-319-72077-7_2.

33. Kirley, T. L., Greis, K. D., and Norman, A. B. (2016) Selective disulfide reduction for labeling and enhancement of Fab antibody fragments, Biochem. Biophys. Res. Commun., 480, 752-757, doi: 10.1016/j.bbrc.2016.10.128.

34. Hudson, P. J., and Kortt, A. A. (1999) High avidity scFv multimers; diabodies and triabodies, J. Immunol. Methods, 231, 177-189, doi: 10.1016/s0022-1759(99)00157-x.

35. Tiller, K. E., and Tessier, P. M. (2015) Advances in antibody design, Annu. Rev. Biomed. Eng., 17, 191-216, doi: 10.1146/annurev-bioeng-071114-040733.

36. Hoogenboom, H. R., Griffiths, A. D., Johnson, K. S., Chiswell, D. J., Hudson, P., et al. (1991) Multi-subunit proteins on the surface of filamentous phage: Methodologies for displaying antibody (Fab) heavy and light chains, Nucleic Acids Res., 19, 4133-4137, doi: 10.1093/nar/19.15. 4133.

37. Gao, C., Mao, S., Lo, C. H., Wirsching, P., Lerner, R. A., et al. (1999) Making artificial antibodies: a format for phage display of combinatorial heterodimeric arrays, Proc. Natl. Acad. Sci. USA, 96, 6025-6030, doi: 10.1073/pnas.96.11. 6025 .
38. Sabir, J. S., Atef, A., El-Domyati, F. M., Edris, S., Hajrah, N., et al. (2014) Construction of naive camelids VHH repertoire in phage display-based library, C. R. Biol., 337, 244-249, doi: 10.1016/j.crvi.2014.02.004.

39. Urquhart, L. (2019) Top drugs and companies by sales in 2018, Nat. Rev. Drug Discov., 18, 245, doi: 10.1038/ d41573-019-00049-0.

40. Alfaleh, M. A., Alsaab, H. O., Mahmoud, A. B., Alkayyal, A. A., Jones, M. L., et al. (2020) Phage display derived monoclonal antibodies: From bench to bedside, Front. Immunol., 11, 1986, doi: 10.3389/fimmu.2020.01986.

41. Ho, M., and Pastan, I. (2009) Mammalian Cell Display for Antibody Engineering, in Therapeutic Antibodies. Methods in Molecular Biology (Methods and Protocols) (Dimitrov, A., ed.) Vol. 525, Humana Press, New Jersey, pp. 337-352, doi: 10.1007/978-1-59745-554-1_18.

42. Löfblom, J. (2011) Bacterial display in combinatorial protein engineering, Biotechnol. J., 6, 1115-1129, doi: 10.1002/ biot.201100129.

43. Cherf, G. M., and Cochran, J. R. (2015) Applications of Yeast Surface Display for Protein Engineering, in Yeast Surface Display. Methods in Molecular Biology (Liu, B., ed.) Vol. 1319, Humana Press, New York, NY, pp. 155-175.

44. Crawford, F., Jordan, K. R., Stadinski, B., Wang, Y., Huseby, E., et al. (2006) Use of baculovirus MHC/peptide display libraries to characterize $\mathrm{T}$-cell receptor ligands, Immunol. Rev., 210, 156-170, doi: 10.1111/j.01052896.2006.00365.x.

45. Walsh, C. T., Garneau-Tsodikova, S., and Gatto, G. J., Jr. (2005) Protein posttranslational modifications: the chemistry of proteome diversifications, Angewandte Chemie Int. Edn. Eng., 44, 7342-7372, doi: 10.1002/anie.200501023.

46. Plückthun, A. (2012) Ribosome Display: A Perspective, in Ribosome Display and Related Technologies. Methods in Molecular Biology (Methods and Protocols) (Douthwaite, J., and Jackson, R., eds.) Vol. 805, Springer, New York, NY, pp. 3-28, doi: 10.1007/978-1-61779-379-0_1.

47. Kamalinia, G., Grindel, B. J., Takahashi, T. T., Millward, S. W., and Roberts, R. W. (2021) Directing evolution of novel ligands by mRNA display, Chem. Soc. Rev., 50, 90559103, doi: 10.1039/D1CS00160D.

48. Rakonjac, J., Russel, M., Khanum, S., Brooke, S. J., and Rajič, M. (2017) Filamentous Phage: Structure and Biology, in Recombinant Antibodies for Infectious Diseases. Advances in Experimental Medicine and Biology (Lim, T., ed.) Vol. 1053, Springer, Cham, pp. 1-20, doi: 10.1007/978-3-319-72077-7_1.

49. Gamkrelidze, M., and Dąbrowska, K. (2014) T4 bacteriophage as a phage display platform, Arch. Microbiol., 196, 473-479, doi: 10.1007/s00203-014-0989-8.

50. Brogan, A. P. S., Heldman, N., Hallett, J. P., and Belcher, A. M. (2019) Thermally robust solvent-free biofluids of M13 bacteriophage engineered for high compatibility with anhydrous ionic liquids, Chem. Commun., 55, 10752-10755, doi: 10.1039/C9CC04909F.

51. Morag, O., Sgourakis, N. G., Baker, D., and Goldbourt, A. (2015) The NMR-Rosetta capsid model of M13 bacteriophage reveals a quadrupled hydrophobic packing epitope, Proc. Natl. Acad. Sci. USA, 112, 971-976, doi: 10.1073/ pnas. 1415393112.

52. Bass, S., Greene, R., and Wells, J. A. (1990) Hormone phage: An enrichment method for variant proteins with 
altered binding properties, Proteins, 8, 309-314, doi: 10.1002/prot.340080405.

53. Bazan, J., Całkosiński, I., and Gamian, A. (2012) Phage display - a powerful technique for immunotherapy: 1 . Introduction and potential of therapeutic applications, Hum. Vacc. Immunother., 8, 1817-1828, doi: 10.4161/hv. 21703.

54. Chasteen, L., Ayriss, J., Pavlik, P., and Bradbury, A. R. (2006) Eliminating helper phage from phage display, Nucleic Acids Res., 34, e145, doi: 10.1093/nar/gkl772.

55. Sidhu, S. S. (2001) Engineering M13 for phage display, Biomol. Eng., 18, 57-63, doi: 10.1016/s1389-0344(01)00087-9.

56. Azzazy, H. M., and Highsmith, W. E., Jr. (2002) Phage display technology: clinical applications and recent innovations, Clin. Biochem., 35, 425-445, doi: 10.1016/s00099120(02)00343-0.

57. Glanville, J., Zhai, W., Berka, J., Telman, D., Huerta, G., et al. (2009) Precise determination of the diversity of a combinatorial antibody library gives insight into the human immunoglobulin repertoire, Proc. Natl. Acad. Sci. USA, 106, 20216-20221, doi: 10.1073/pnas.0909775106.

58. Briney, B., Inderbitzin, A., Joyce, C., and Burton, D. R. (2019) Commonality despite exceptional diversity in the baseline human antibody repertoire, Nature, 566, 393-397, doi: 10.1038/s41586-019-0879-y.

59. Osajima, T., and Hoshino, T. (2016) Roles of the respective loops at complementarity determining region on the antigen-antibody recognition, Computat. Biol. Chem., 64, 368383, doi: 10.1016/j.compbiolchem.2016.08.004.

60. Babor, M., and Kortemme, T. (2009) Multi-constraint computational design suggests that native sequences of germline antibody $\mathrm{H} 3$ loops are nearly optimal for conformational flexibility, Proteins, 75, 846-858, doi: 10.1002/ prot.22293.

61. Kuroda, D., Shirai, H., Kobori, M., and Nakamura, H. (2008) Structural classification of CDR-H3 revisited: A lesson in antibody modeling, Proteins, 73, 608-620, doi: 10.1002/prot.22087.

62. Fellouse, F. A., Esaki, K., Birtalan, S., Raptis, D., Cancasci, V. J., et al. (2007) High-throughput generation of synthetic antibodies from highly functional minimalist phage-displayed libraries, J. Mol. Biol., 373, 924-940, doi: 10.1016/j.jmb.2007.08.005.

63. Adler, A. S., Mizrahi, R. A., Spindler, M. J., Adams, M. S., Asensio, M. A., et al. (2017) Rare, high-affinity antipathogen antibodies from human repertoires, discovered using microfluidics and molecular genomics, $m A b s, 9$, 1282-1296, doi: 10.1080/19420862.2017.1371383.

64. Gérard, A., Woolfe, A., Mottet, G., Reichen, M., Castrillon, C., et al. (2020) High-throughput single-cell activity-based screening and sequencing of antibodies using droplet microfluidics, Nat. Biotechnol., 38, 715-721, doi: 10.1038/s41587-020-0466-7.

65. Chan, S. K., Rahumatullah, A., Lai, J. Y., and Lim, T. S. (2017) Naïve Human Antibody Libraries for Infectious Diseases, in Recombinant Antibodies for Infectious Diseases. Advances in Experimental Medicine and Biology (Lim, T., ed.) Vol. 1053, Springer, Cham, pp. 35-59, doi: 10.1007/978-3-319-72077-7_3.

66. Bashir, S., and Paeshuyse, J. (2020) Construction of antibody phage libraries and their application in veterinary immunovirology, Antibodies (Basel), 9, 21, doi: 10.3390/antib9020021.
67. Binz, H. K., and Plückthun, A. (2005) Engineered proteins as specific binding reagents, Curr. Opin. Biotechnol., 16, 459-469, doi: 10.1016/j.copbio.2005.06.005.

68. Ahmadi, M. K. B., Mohammadi, S. A., Makvandi, M., Mamouei, M., Rahmati, M., et al. (2021) Recent advances in the scaffold engineering of protein binders, Curr. Pharm. Biotechnol., 22, 878-891, doi: 10.2174/ 1389201021999200824101035.

69. Sidhu, S. S., and Fellouse, F. A. (2006) Synthetic therapeutic antibodies, Nat. Chem. Biol., 2, 682-688, doi: 10.1038/ nchembio843.

70. Adams, J. J., and Sidhu, S. S. (2014) Synthetic antibody technologies, Curr. Opin. Struct. Biol., 24, 1-9, doi: 10.1016/j.sbi.2013.11.003.

71. Nissim, A., Hoogenboom, H. R., Tomlinson, I. M., Flynn, G., Midgley, C., et al. (1994) Antibody fragments from a "single pot" phage display library as immunochemical reagents, EMBO J., 13, 692-698.

72. Yang, H. Y., Kang, K. J., Chung, J. E., and Shim, H. (2009) Construction of a large synthetic human scFv library with six diversified CDRs and high functional diversity, Mol. Cells, 27, 225-235, doi: 10.1007/s10059-009-0028-9.

73. Knappik, A., Ge, L., Honegger, A., Pack, P., Fischer, M., et al. (2000) Fully synthetic human combinatorial antibody libraries (HuCAL) based on modular consensus frameworks and CDRs randomized with trinucleotides, $\mathrm{J}$. Mol. Biol., 296, 57-86, doi: 10.1006/jmbi.1999.3444.

74. Van den Brulle, J., Fischer, M., Langmann, T., Horn, G., Waldmann, T., et al. (2008) A novel solid phase technology for high-throughput gene synthesis, Biotechniques, 45, 340343, doi: 10.2144/000112953.

75. Silacci, M., Brack, S., Schirru, G., Mårlind, J., Ettorre, A., et al. (2005) Design, construction, characterization of a large synthetic human antibody phage display library, Proteomics, 5, 2340-2350, doi: 10.1002/pmic.200401273.

76. Tiller, T., Schuster, I., Deppe, D., Siegers, K., Strohner, R., et al. (2013) A fully synthetic human Fab antibody library based on fixed VH/VL framework pairings with favorable biophysical properties, $m A b s, 5,445-470$, doi: 10.4161/ mabs. 24218 .

77. Rothe, C., Urlinger, S., Löhning, C., Prassler, J., Stark, Y., et al. (2008) The human combinatorial antibody library HuCAL GOLD combines diversification of all six CDRs according to the natural immune system with a novel display method for efficient selection of high-affinity antibodies, J. Mol. Biol., 376, 1182-1200, doi: 10.1016/j.jmb.2007. 12.018.

78. Bai, X., and Shim, H. (2017) Construction of a scFv Library with Synthetic, Non-combinatorial CDR Diversity, in Synthetic Antibodies. Methods in Molecular Biology (Tiller, T. ed.) vol. 1575, Humana Press, New York, NY, pp. 15-29, doi: 10.1007/978-1-4939-6857-2_2.

79. Fellouse, F. A., Li, B., Compaan, D. M., Peden, A. A., Hymowitz, S. G., et al. (2005) Molecular recognition by a binary code, J. Mol. Biol., 348, 1153-1162, doi: 10.1016/ j.jmb.2005.03.041.

80. Kunkel, T. A., Bebenek, K., and McClary, J. (1991) Efficient site-directed mutagenesis using uracil-containing DNA, Methods Enzymol., 204, 125-139, doi: 10.1016/ 0076-6879(91)04008-c.

81. Paduch, M., Koide, A., Uysal, S., Rizk, S. S., Koide, S., et al. (2013) Generating conformation-specific synthetic 
antibodies to trap proteins in selected functional states, Methods, 60, 3-14, doi: 10.1016/j.ymeth.2012.12.010.

82. Paduch, M., Kossiakoff, A. A. (2017) Generating Conformation and Complex-Specific Synthetic Antibodies, In: Synthetic Antibodies. Methods in Molecular Biology (Tiller T. ed.), vol. 1575, Humana Press, New York, NY, pp. 93-119, doi: 10.1007/978-1-4939-6857-2_6.

83. Ye, J. D., Tereshko, V., Frederiksen, J. K., Koide, A., Fellouse, F. A., et al. (2008) Synthetic antibodies for specific recognition and crystallization of structured RNA, Proc. Natl. Acad. Sci. USA, 105, 82-87, doi: 10.1073/pnas. 0709082105.

84. Shao, Y., Huang, H., Qin, D., Li, N. S., Koide, A., et al. (2016) Specific recognition of a single-stranded RNA sequence by a synthetic antibody fragment, J. Mol. Biol., 428, 4100-4114, doi: 10.1016/j.jmb.2016.08.029.

85. Slezak, T., and Kossiakoff, A. A. (2021) Engineered ultrahigh affinity synthetic antibodies for SARS-CoV-2 neutralization and detection, J. Mol. Biol., 433, 166956, doi: 10.1016/j.jmb.2021.166956.

86. Mukherjee, S., Erramilli, S. K., Ammirati, M., Alvarez, F. J. D., Fennell, K. F., et al. (2020) Synthetic antibodies against BRIL as universal fiducial marks for single-particle cryoEM structure determination of membrane proteins, Nat. Commun., 11, 1598, doi: 10.1038/s41467-020-15363-0.

87. Dutka, P., Mukherjee, S., Gao, X., Kang, Y., de Waal, P. W., et al. (2019) Development of "plug and play" fiducial marks for structural studies of GPCR signaling complexes by single-particle Cryo-EM, Structure, 27, 1862-1874.e7, doi: 10.1016/j.str.2019.10.004.

88. Mukherjee, S., Griffin, D. H., Horn, J. R., Rizk, S. S., Nocula-Lugowska, M., et al. (2018) Engineered synthetic antibodies as probes to quantify the energetic contributions of ligand binding to conformational changes in proteins, J. Biol. Chem., 293, 2815-2828, doi: 10.1074/jbc.RA117. 000656.

89. Radwańska, M. J., Jaskółowski, M., Davydova, E., Derewenda, U., Miyake, T., et al. (2018) The structure of the C-terminal domain of the nucleoprotein from the Bundibugyo strain of the Ebola virus in complex with a pan-specific synthetic Fab, Acta Crystallogr. Sect. D Struct. Biol., 74, 681-689, doi: 10.1107/S2059798318007878.

90. Rizk, S. S., Mukherjee, S., Koide, A., Koide, S., and Kossiakoff, A. A. (2017) Targeted rescue of cancer-associated IDH1 mutant activity using an engineered synthetic antibody, Sci. Rep., 7, 556, doi: 10.1038/s41598-01700728-1.

91. Dominik, P. K., Borowska, M. T., Dalmas, O., Kim, S. S., Perozo, E., et al. (2016) Conformational chaperones for structural studies of membrane proteins using antibody phage display with nanodiscs, Structure, 24, 300-309, doi: 10.1016/j.str.2015.11.014.

92. Rizk, S. S., Kouadio, J. L., Szymborska, A., Duguid, E. M., Mukherjee, S., et al. (2015) Engineering synthetic antibody binders for allosteric inhibition of prolactin receptor signaling, Cell Commun. Signal., 13, 1, doi: 10.1186/ s12964-014-0080-8.

93. Rizk, S. S., Paduch, M., Heithaus, J. H., Duguid, E. M., Sandstrom, A., et al. (2011) Allosteric control of ligandbinding affinity using engineered conformation-specific effector proteins, Nat. Struct. Mol. Biol., 18, 437-442, doi: $10.1038 /$ nsmb.2002.
94. Brawley, C. M., Uysal, S., Kossiakoff, A. A., and Rock, R. S. (2010) Characterization of engineered actin binding proteins that control filament assembly and structure, PLoS One, 5, e13960, doi: 10.1371/journal.pone.0013960.

95. Yu, Y., Zheng, Q., Erramilli, S. K., Pan, M., Park, S., et al. (2021) K29-linked ubiquitin signaling regulates proteotoxic stress response and cell cycle, Nat. Chem. Biol., 17, 896905, doi: 10.1038/s41589-021-00823-5.

96. Nocula-Lugowska, M., Lugowski, M., Salgia, R., and Kossiakoff, A. A. (2015) Engineering synthetic antibody inhibitors specific for LD2 or LD4 motifs of paxillin, J. Mol. Biol., 427, 2532-2547, doi: 10.1016/j.jmb.2015. 06.004.

97. Sun, J., Paduch, M., Kim, S. A., Kramer, R. M., Barrios, A. F., et al. (2018) Structural basis for activation of SAGA histone acetyltransferase Gcn5 by partner subunit Ada2, Proc. Natl. Acad. Sci. USA, 115, 10010-10015, doi: $10.1073 /$ pnas. 1805343115 .

98. Mateja, A., Paduch, M., Chang, H. Y., Szydlowska, A., Kossiakoff, A. A., et al. (2015) Protein targeting. Structure of the Get3 targeting factor in complex with its membrane protein cargo, Science, 347, 1152-1155, doi: 10.1126/science. 1261671.

99. Shukla, A. K., Manglik, A., Kruse, A. C., Xiao, K., Reis, R. I., et al. (2013) Structure of active beta-arrestin-1 bound to a G-protein-coupled receptor phosphopeptide, Nature, 497, 137-141, doi: 10.1038/nature12120.

100. Lokareddy, R. K., Ko, Y. H., Hong, N., Doll, S. G., Paduch, M., et al. (2020) Recognition of an alpha-helical hairpin in P22 large terminase by a synthetic antibody fragment, Acta Crystallogr. Sect. D Struct. Biol., 76, 876888, doi: $10.1107 /$ S2059798320009912.

101. Carmen, S., and Jermutus, L. (2002) Concepts in antibody phage display, Brief. Funct. Genom. Proteomics, 1, 189-203, doi: $10.1093 / \mathrm{bfgp} / 1.2 .189$.

102. Green, N. M. (1990) Avidin and streptavidin, Methods Enzymol., 184, 51-67, doi: 10.1016/0076-6879(90)84259-j.

103. Dundas, C. M., Demonte, D., and Park, S. (2013) Streptavidin-biotin technology: improvements and innovations in chemical and biological applications, Appl. Microbiol. Biotechnol., 97, 9343-9353, doi: 10.1007/ s00253-013-5232-z.

104. Chattopadhaya, S., Abu Bakar, F. B., and Yao, S. Q. (2009) Expanding the chemical biologist's tool kit: Chemical labelling strategies and its applications, Curr. Med. Chem., 16, 4527-4543, doi: 10.2174/092986709789760706.

105. Tirat, A., Freuler, F., Stettler, T., Mayr, L. M., and Leder, L. (2006) Evaluation of two novel tag-based labelling technologies for site-specific modification of proteins, Int. J. Biol. Macromol., 39, 66-76, doi: 10.1016/ j.ijbiomac.2006.01.012.

106. Scholle, M. D., Collart, F. R., and Kay, B. K. (2004) In vivo biotinylated proteins as targets for phage-display selection experiments, Protein Express. Purif., 37, 243252, doi: 10.1016/j.pep.2004.05.012.

107. Young, C. L., Britton, Z. T., and Robinson, A. S. (2012) Recombinant protein expression and purification: a comprehensive review of affinity tags and microbial applications, Biotechnol. J., 7, 620-634, doi: 10.1002/biot. 201100155.

108. Dąbrowska, K. (2019) Isolation of Competitive Phage Display-Modified Bacteriophage T4 with Affinity 
Chromatography, In: Bacteriophages. Methods in Molecular Biology (Clokie, M., Kropinski, A., Lavigne, R., eds.), vol. 1898, Humana Press, New York, NY, pp. 81-87, doi: 10.1007/978-1-4939-8940-9_7.

109. Beckmann, C., Haase, B., Timmis, K. N., and Tesar, M. (1998) Multifunctional g3p-peptide tag for current phage display systems, J. Immunol. Methods, 212, 131-138, doi: 10.1016/s0022-1759(98)00008-8.

110. Hussack, G., Baral, T. N., Baardsnes, J., van Faassen, H., Raphael, S., et al. (2017) A novel affinity Tag, ABTAG, its application to the affinity screening of single-domain antibodies selected by phage display, Front. Immunol., 8, 1406, doi: 10.3389/fimmu.2017.01406.

111. Mukherjee, S., Ura, M., Hoey, R. J., and Kossiakoff, A. A. (2015) A new versatile immobilization tag based on the ultra high affinity and reversibility of the calmodulin-calmodulin binding peptide interaction, J. Mol. Biol., 427, 2707-2725, doi: 10.1016/j.jmb.2015. 06.018.

112. Passariello, M., Gentile, C., Ferrucci, V., Sasso, E., Vetrei, C., et al. (2021) Novel human neutralizing mAbs specific for Spike-RBD of SARS-CoV-2, Sci. Rep., 11, 11046, doi: 10.1038/s41598-021-90348-7.

113. Krishnaswamy, S., Kabir, M. E., Miyamoto, M., Furuichi, Y., and Komiyama, T. (2009) Cloning antifungal single chain fragment variable antibodies by phage display and competitive panning elution, Anal. Biochem., 395, 1624, doi: 10.1016/j.ab.2009.08.003.

114. Caberoy, N. B., Zhou, Y., Jiang, X., Alvarado, G., and Li, W. (2010) Efficient identification of tubby-binding proteins by an improved system of T7 phage display, J. Mol. Recognit., 23, 74-83, doi: 10.1002/jmr.983.

115. Urh, M., and Rosenberg, M. (2012) HaloTag, a platform technology for protein analysis, Curr. Chem. Genom., 6, 7278, doi: 10.2174/1875397301206010072.

116. England, C. G., Luo, H., and Cai, W. (2015) HaloTag technology: a versatile platform for biomedical applications, Bioconj. Chem., 26, 975-986, doi: 10.1021/acs.bioconjchem.5b00191.

117. Engin, S., Fichtner, D., Wedlich, D., and Fruk, L. (2013) SNAP-tag as a tool for surface immobilization, Curr. Pharm. Design, 19, 5443-5448, doi: 10.2174/1381612811319300015.

118. Hinner, M. J., and Johnsson, K. (2010) How to obtain labeled proteins and what to do with them, Curr. Opin. Biotechnol., 21, 766-776, doi: 10.1016/j.copbio.2010. 09.011 .

119. Gautier, A., Juillerat, A., Heinis, C., Corrêa, I. R., Jr., Kindermann, M., et al. (2008) An engineered protein tag for multiprotein labeling in living cells, Chem. Biol., 15, 128-136, doi: 10.1016/j.chembiol.2008.01.007.

120. Reymond, L., Lukinavičius, G., Umezawa, K., Maurel, D., Brun, M. A., et al. (2011) Visualizing biochemical activities in living cells through chemistry, Chimia (Aarau), 65, 868-871, doi: 10.2533/chimia. 2011.868.

121. Zhou, C., Yan, Y., Fang, J., Cheng, B., and Fan, J. (2014) A new fusion protein platform for quantitatively measuring activity of multiple proteases, Microb. Cell Factor., 13, 44, doi: 10.1186/1475-2859-13-44.

122. Costa, S. J., Coelho, E., Franco, L., Almeida, A., Castro, A., et al. (2013) The Fh8 tag: a fusion partner for simple and cost-effective protein purification in
Escherichia coli, Protein Express. Purif., 92, 163-170, doi: 10.1016/j.pep.2013.09.013.

123. Slezak, T., Bailey, L. J., Jaskolowski, M., Nahotko, D. A., Filippova, E. V., et al. (2020) An engineered ultra-high affinity Fab-Protein $\mathrm{G}$ pair enables a modular antibody platform with multifunctional capability, Protein Sci., 29, 141-156, doi: 10.1002/pro.3751.

124. Hornsby, M., Paduch, M., Miersch, S., Sääf, A., Matsuguchi, T., et al. (2015) A high Through-put Platform for recombinant antibodies to folded proteins, Mol. Cell. Proteomics, 14, 2833-2847, doi: 10.1074/mcp.O115. 052209.

125. Welch, B. D., Paduch, M., Leser, G. P., Bergman, Z., Kors, C. A., et al. (2014) Probing the functions of the paramyxovirus glycoproteins $\mathrm{F}$ and $\mathrm{HN}$ with a panel of synthetic antibodies, J. Virol., 88, 11713-11725, doi: 10.1128/JVI.01707-14.

126. Farcasanu, M., Wang, A. G., Uchański, T., Bailey, L. J., Yue, J., et al. (2019) Rapid discovery and characterization of synthetic neutralizing antibodies against Anthrax Edema toxin, Biochemistry, 58, 2996-3004, doi: 10.1021/ acs.biochem.9b00184.

127. Miller, E. A., Sung, K. J., Kongsuphol, P., Baniya, S., AwYong, H. Q., et al. (2020) Beyond epitope binning: Directed in vitro selection of complementary pairs of binding proteins, ACS Combinat. Sci., 22, 49-60, doi: 10.1021/ acscombsci.9b00176.

128. Nilvebrant, J. (2018) Kinetic Analysis and Epitope Binning Using Surface Plasmon Resonance, in Epitope Mapping Protocols. Methods in Molecular Biology (Rockberg, J., and Nilvebrant, J., eds.) Vol. 1785, Humana Press, New York, NY, pp. 187-205, doi: 10.1007/978-14939-7841-0_12.

129. Frank, J. (2002) Single-particle imaging of macromolecules by cryo-electron microscopy, Annu. Rev. Biophys. Biomol. Struct., 31, 303-319, doi: 10.1146/annurev.biophys.31.082901.134202.

130. Koldobskaya, Y., Duguid, E. M., Shechner, D. M., Suslov, N. B., Ye, J., et al. (2011) A portable RNA sequence whose recognition by a synthetic antibody facilitates structural determination, Nat. Struct. Mol. Biol., 18, 100-106, doi: 10.1038/nsmb.1945.

131. Stuwe, T., Correia, A. R., Lin, D. H., Paduch, M., Lu, V. T., et al. (2015) Nuclear pores. Architecture of the nuclear pore complex coat, Science, 347, 1148-1152, doi: 10.1126/science.aaa4136.

132. Dominik, P. K., and Kossiakoff, A. A. (2015) Phage display selections for affinity reagents to membrane proteins in nanodiscs, Methods Enzymol., 557, 219-245, doi: 10.1016/bs.mie.2014.12.032.

133. Denisov, I. G., and Sligar, S. G. (2016) Nanodiscs for structural and functional studies of membrane proteins, Nat. Struct. Mol. Biol., 23, 481-486, doi: 10.1038/nsmb. 3195.

134. Bayburt, T. H., and Sligar, S. G. (2010) Membrane protein assembly into nanodiscs, FEBS Lett., 584, 1721-1727, doi: 10.1016/j.febslet.2009.10.024.

135. Shen, P. S. (2018) The 2017 Nobel Prize in Chemistry: Cryo-EM comes of age, Anal. Bioanal. Chem., 410, 20532057, doi: 10.1007/s00216-018-0899-8.

136. Peters, R., and Sikorski, R. (1999) Difference mapping cryoEM, Science, 283, 1133, doi: 10.1126/science.283.5405.1133a. 
137. Frank, J. (2001) Cryo-electron microscopy as an investigative tool: The ribosome as an example, Bioessays, 23, 725-732, doi: 10.1002/bies.1102.

138. Cheng, Y. (2018) Single-particle cryo-EM-How did it get here and where will it go, Science, 361, 876-880, doi: $10.1126 /$ science.aat4346.

139. Wu, M., and Lander, G. C. (2020) How low can we go? Structure determination of small biological complexes using single-particle cryo-EM, Curr. Opin. Struct. Biol., 64, 9-16, doi: 10.1016/j.sbi.2020.05.007.

140. Uchański, T., Masiulis, S., Fischer, B., Kalichuk, V., López-Sánchez, U., et al. (2021) Megabodies expand the nanobody toolkit for protein structure determination by single-particle cryo-EM, Nat. Methods, 18, 60-68, doi: 10.1038/s41592-020-01001-6.

141. Wu, X., and Rapoport, T. A. (2021) Cryo-EM structure determination of small proteins by nanobody-binding scaffolds (Legobodies), Proc. Natl. Acad. Sci. USA, 118, e2115001118, doi: 10.1073/pnas.2115001118.

142. Kang, Y., Kuybeda, O., de Waal, P. W., Mukherjee, S., Van Eps, N., et al. (2018) Cryo-EM structure of human rhodopsin bound to an inhibitory G protein, Nature, 558, 553-558, doi: 10.1038/s41586-018-0215-y.

143. Koehl, A., Hu, H., Maeda, S., Zhang, Y., Qu, Q., et al. (2018) Structure of the micro-opioid receptor-Gi protein complex, Nature, 558, 547-552, doi: 10.1038/s41586-0180219-7.

144. Maeda, S., Koehl, A., Matile, H., Hu, H., Hilger, D., et al. (2018) Development of an antibody fragment that stabilizes GPCR/G-protein complexes, Nat. Commun., 9, 3712, doi: 10.1038/s41467-018-06002-w.

145. Chun, E., Thompson, A. A., Liu, W., Roth, C. B., Griffith, M. T., et al. (2012) Fusion partner toolchest for the stabilization and crystallization of $\mathrm{G}$ protein-coupled receptors, Structure, 20, 967-976, doi: 10.1016/j.str.2012. 04.010 .

146. Vasiliauskaité-Brooks, I., Healey, R. D., Rochaix, P., Saint-Paul, J., Sounier, R., et al. (2018) Structure of a human intramembrane ceramidase explains enzymatic dysfunction found in leukodystrophy, Nat. Commun., 9, 5437, doi: 10.1038/s41467-018-07864-w.

147. Zheng, S., Sham, L. T., Rubino, F. A., Brock, K. P., Robins, W. P., et al. (2018) Structure and mutagenic analysis of the lipid II flippase MurJ from Escherichia coli, Proc. Natl. Acad. Sci. USA, 115, 6709-6714, doi: 10.1073/pnas. 1802192115.
148. Bailey, L. J., Sheehy, K. M., Dominik, P. K., Liang, W. G., Rui, H., et al. (2018) Locking the elbow: Improved antibody Fab fragments as chaperones for structure determination, J. Mol. Biol., 430, 337-347, doi: 10.1016/j.jmb.2017. 12.012 .

149. Schaefer, Z. P., Bailey, L. J., Kossiakoff, A. A. (2016) A polar ring endows improved specificity to an antibody fragment, Protein Sci., 25, 1290-1298, doi: 10.1002/pro.2888.

150. Nordenfelt, P., and Björck, L. (2013) IgG-binding bacterial proteins and pathogenesis, Future Microbiol., 8, 299301, doi: $10.2217 / \mathrm{fmb} .13 .6$.

151. Bouvet, J. P. (1994) Immunoglobulin Fab fragment-binding proteins, Int. J. Immunopharmacol., 16, 419-424, doi: 10.1016/0192-0561(94)90031-0.

152. Housden, N. G., Harrison, S., Roberts, S. E., Beckingham, J. A., Graille, M., et al. (2003) Immunoglobulin-binding domains: Protein L from Peptostreptococcus magnus, Biochem. Soc. Trans., 31, 716-718, doi: $10.1042 /$ bst0310716.

153. Rigi, G., Ghaedmohammadi, S., and Ahmadian, G. (2019) A comprehensive review on staphylococcal protein A (SpA): Its production and applications, Biotechnol. Appl. Biochem., 66, 454-464, doi: 10.1002/bab.1742.

154. Jaturapaktrarak, C., Payattikul, P., Lohnoo, T., Kumsang, Y., Laikul, A., et al. (2020) Protein A/G-based enzyme-linked immunosorbent assay for detection of antiPythium insidiosum antibodies in human and animal subjects, BMC Res. Notes, 13, 135, doi: 10.1186/s13104-02004981-y.

155. Eliasson, M., Olsson, A., Palmcrantz, E., Wiberg, K., Inganäs, M., et al. (1988) Chimeric IgG-binding receptors engineered from staphylococcal protein A and streptococcal protein G, J. Biol. Chem., 263, 4323-4327.

156. Sheng, S., and Kong, F. (2012) Separation of antigens and antibodies by immunoaffinity chromatography, Pharmaceut. Biol., 50, 1038-1044, doi: 10.3109/13880209.2011.653493.

157. Bailey, L. J., Sheehy, K. M., Hoey, R. J., Schaefer, Z. P., Ura, M., et al. (2014) Applications for an engineered Protein-G variant with a $\mathrm{pH}$ controllable affinity to antibody fragments, J. Immunol. Methods, 415, 24-30, doi: $10.1016 /$ j.jim.2014.10.003.

158. Galarneau, A., Primeau, M., Trudeau, L. E., and Michnick, S. W. (2002) Beta-lactamase protein fragment complementation assays as in vivo and in vitro sensors of protein-protein interactions, Nat. Biotechnol., 20, 619622, doi: 10.1038/nbt0602-619. 